\title{
Unobservable Monetary Policy Surprises and Exchange Rates
}

\author{
Vahid Gholampour ${ }^{1}$ \\ ${ }^{1}$ Economics Department, Bucknell University, Pennsylvania, United States \\ Correspondence: Vahid Gholampour, Academic West building, Bucknell University, Lewisburg, Pennsylvania, \\ 17837, United States.
}

Received: November 25, 2020

Accepted: January 19, 2021

Online Published: January 22, 2021

doi:10.5430/afr.v10n1p11

URL: https://doi.org/10.5430/afr.v10n1p11

\begin{abstract}
The paper examines the effect of monetary policy statement shocks on exchange rates. I use Google's Natural Language tools to measure and track changes in the sentiment of FOMC and ECB post-meeting statements. The results reveal a negative relationship between the dollar's value and FOMC statement shocks. Investors sell (buy) the dollar when the sentiment of the FOMC statement is more positive (negative) than the previous one. This negative relationship could be explained by the special status of the U.S. dollar as a safe-haven currency and the significant effect of U.S. monetary policy on other countries' macroeconomic fundamentals. The value of the euro is positively related to ECB statement shocks. The size of the exchange rate response to statement shocks is comparable to that of term structure shocks. There is no material difference between the response of exchange rates in conventional and unconventional times. Statement shocks affect the exchange rates through the information channel.
\end{abstract}

Keywords: exchange rate, monetary policy statement, machine learning, natural language processing

\section{Introduction}

Major central banks usually release a statement after their monetary policy meetings. The statements often provide central bankers' assessment of the economy's current state and policymakers' outlook for medium to long-term economic fundamentals and monetary policy. Private sector agents update their expectations of macroeconomic fundamentals based on the information content of the statements and trade currencies. There is empirical evidence for large changes in dollar and euro exchange rates on FOMC and ECB policy announcement days (Jansen \& Haan, 2005; Mueller, Tahbaz-Salehi, \& Vedolin, 2017). Surprises in monetary policy statements are unobservable to econometricians. The primary challenge in extracting information from the statements is that objective analysis of the information embedded in the statements is not an easy task, and various individuals might interpret the same sentence differently. This paper overcomes this challenge by using an objective machine learning tool to track changes in the statements. The results of this study help market participants and policymakers better understand the link between the sentiment of monetary policy statements and exchange rates.

\subsection{Statement of Research Questions}

This paper focuses on three questions.

1) Can the structure and meaning of words used in monetary policy statements account for some of the large changes in exchange rates on announcement days?

2) Is the effect of statement shocks on exchange rates economically significant?

3) What is the primary channel through which statement shocks affect exchange rates?

The first question is answered by breaking down monetary policy shocks to term structure and statement shocks and measuring the response of exchange rates to the statement shocks. Term structure shocks are changes in interest rates across different maturities on monetary policy announcement days. The paper defines statement shocks as changes in the sentiment of monetary policy statements. Nakamura and Steinsson (2018) show that monetary policy announcements cause private sector agents to update their future real output expectations. They demonstrate that the information effect is quite substantial. The effect of statements on the term structure of interest rates has been studied extensively in the literature. See Romer and Romer (2000), Kuttner (2001), Gürkaynak, Sack, \& Swanson (2005), and Inoue and Rossi (2019). This paper's results show that changes in the sentiment of statements lead to changes in exchange rates after controlling for the effect of term structure shocks. The paper uses Google Cloud's Natural Language API to measure monetary policy statements' sentiment and track their changes. An API, or Application 
Programming Interface, is essentially a way for applications to borrow functionality and data from each other. Natural Language API enables developers to use Google's pre-trained models to analyze the sentiment of a block of text. The Natural Language API uses deep machine learning technology to reveal the structure and meaning of the text. The main advantage of a pre-trained Natural Language API over alternatives is its objectivity in detecting the sentiment of the text. The paper focuses on the effect of FOMC and ECB monetary policy statements on dollar and euro exchange rates. I measure the response of exchange rates to statement and term structure shocks by estimating the parameters of a VAR model.

The results show that the U.S. dollar depreciates (appreciates) following positive (negative) statement shocks. Investors sell the dollar and buy other currencies when the FOMC statement is more positive than the previous one. This negative relationship between the value of the dollar and FOMC statements' sentiment could be explained by the significant effect of U.S. monetary policy on economic fundamentals in other countries. Maćkowiak (2007) shows that the price level and real output in a typical emerging market respond to U.S. monetary policy shocks by more than the price level and real output in the U.S. itself. When the FOMC statement is more positive than before, private sector agents raise their expectations of U.S. fundamentals, but their expectations of other countries' fundamentals rise more, and they sell the dollar to buy other currencies. The special status of the dollar as the safe-haven currency could also explain this negative relationship. The results for euro exchange rates reveal a positive relationship between the value of the euro and changes in ECB statements' sentiment. The effect of statement shocks on dollar and euro exchange rates are quantitatively similar in conventional and unconventional monetary policy periods. Moreover, statement shocks lead to a change in exchange rates following both contractionary and expansionary monetary policy announcements.

The second question is related to the economic significance of the effect of statement shocks on exchange rates. The average impulse response of various exchange rates to statement shocks is between 5 and 12 basis points. Gürkaynak et al. (2005) show that monetary policy announcements lead to significant changes in interest rates, especially for longer horizons. In order to put the size of the exchange rate response to statement shocks in perspective, the effect of term structure shocks on exchange rates is compared with the effect of statement shocks. The results indicate that term structure shocks cause exchange rates to change by 2 to 17 basis points. The conclusion is that the effect of statement shocks is comparable to that of term structure shocks and is economically significant.

The paper addresses the third question by examining various transmission channels and their plausibility to account for the effect of statement shocks on exchange rates.

First, let us consider the information channel. A central bank can influence the private sector's expectations by changing its forecast of key economic indicators. Another way that the central bank could affect the expectations is by changing the tone of its monetary policy statements. The results section shows that revisions to Fed forecasts impact exchange rates, but the effect of statement shocks is mostly intact after controlling for the effect of Fed forecast revisions. Changes in the sentiment of statements lead to changes in exchange rates beyond what could be explained by changes in expectations of short-term interest rates and revisions to the Fed's forecast of U.S. economic fundamentals. The response of dollar exchange rates to statement shocks indicate that the sentiment of Fed statements influences expectations of future domestic and international economic fundamentals. Given that Fed statements often mention international developments, it is reasonable to think that private sector agents update their expectations of future macro fundamentals for the U.S. and other countries following a change in the sentiment of the FOMC statement.

Second, monetary policy uncertainty may lead to somewhat predictable changes in exchange rates on announcement days. Mueller et al. (2017) show that a trading strategy that takes a short position on the U.S. dollar on Fed announcement days generates a significant excess return. They attribute the sizeable gain of this trading strategy to monetary policy uncertainty. If the effect of statement shocks on exchange rates results from monetary policy uncertainty, the dollar should depreciate on announcement days regardless of the direction of change in the sentiment of the statement. This paper clearly shows that the response of exchange rates depends on the sign of statement shocks. Finally, one could argue that the interpretation of statements is inherently difficult, and different agents might interpret the same statement differently. Consequently, the effect of statements on the exchange rate is nothing more than the risk premium priced in exchange rates due to monetary policy statements' ambiguity. If the ambiguity premium gets priced in exchange rates, the direction of change in dollar exchange rates on announcement days should not be a function of the direction of change in the sentiment of the statement. The evidence in this paper does not support this prediction. Therefore, the ambiguity of statements is not a plausible explanation for the effect of statement shocks on exchange rates. 


\subsection{Literature Review}

This paper is related to the vast literature that examines the effect of monetary policy on asset prices. In their seminal work, Gürkaynak et al. (2005) discuss the possibility of several dimensions in monetary policy surprises. In a recent paper, Inoue and Rossi (2019) measure the effect of term structure shocks on exchange rates. The novelty of their functional vector autoregression (VAR) approach is that it captures the effects of shocks on the entire term structure on exchange rates. This approach is different from the standard three-factor yield curve models or four-factor models such as De Pooter (2007) and Cochrane and Piazzesi (2009).

This paper is not the first study that investigates the relationship between monetary policy statements and exchange rates. Jensen and Haan (2005) and Conrad and Lamla (2010) examine the link between ECB statements and the euro/dollar exchange rate. Hausman and Wongswan (2011) investigate the effect of FOMC announcements on equity indexes, exchange rates, and other countries' interest rates. Lucca and Trebbi (2009) highlight the effect of FOMC statements on long-term Treasuries. To my knowledge, this is the first paper that uses an objective machine learning tool to measure shocks to monetary policy statements and finds the response of exchange rates to these shocks. The rest of the paper is organized as follows. Section 2 provides some details about data sources and monetary policy meetings of the two major central banks. The section also describes the methodology of measuring the response of exchange rates to term structure and statement shocks. Section 3 provides the results. Section 4 discusses the results and concludes.

\section{Method}

\subsection{Data}

To study the effect of statement shocks on exchange rates, we need data on exchange rates, monetary policy meeting dates, and the transcript of monetary policy statements and press conferences. We also need interest rate data of dollar and euro-denominated zero-coupon bonds of various maturities. Monetary policy meeting dates and the transcript of statements are obtained from the FRB and ECB websites. This study considers post-meeting statements from January 2000 to June 2016. Daily spot exchange rate data is from Bloomberg. The rates are the closing rates in London. The exchange rates are expressed as Foreign currency per unit of Home currency. For instance, USD/JPY is the exchange rate of the Japanese Yen for one U.S. dollar. An increase in the exchange rate represents an appreciation of the U.S. dollar vis-à-vis the yen. The daily dollar interest rates for various maturities are from Gürkaynak, Sack, and Wright (2007). The euro rates are from the ECB website. The availability of the data dictates the frequency of exchange rates and interest rates. Sections 2.2 and 2.3 provide some details about FOMC and ECB monetary policy statements.

\subsection{FOMC Monetary Policy Statements}

Members of the Federal Open Market Committee (FOMC) usually meet on pre-scheduled dates to discuss the appropriate monetary policy for the United States economy and release a statement after their meetings. The market often anticipates the short-term interest rate decision. Market participants pay close attention to post-meeting statements to learn about the future direction of monetary policy. The primary challenge in analyzing the statements is that an objective analysis is complicated. Moreover, different investors might interpret the same statement differently due to their biases and prior beliefs. This paper uses an objective machine learning tool to measure changes in the sentiment of monetary policy statements. More specifically, the paper employs Google's Natural Language tools to measure the sentiment of statements.

Table1. Number of monetary policy meetings held by central bank in the United States and Europe

\begin{tabular}{lll}
\hline & FOMC & ECB \\
\hline 2000 & 8 & 24 \\
2001 & 11 & 24 \\
2002 & 8 & 12 \\
2003 & 8 & 12 \\
2004 & 8 & 12 \\
2005 & 8 & 12 \\
2006 & 8 & 12 \\
2007 & 10 & 12
\end{tabular}




\begin{tabular}{lll}
\hline 2008 & 11 & 12 \\
2009 & 8 & 12 \\
2010 & 9 & 12 \\
2011 & 8 & 12 \\
2012 & 8 & 12 \\
2013 & 8 & 12 \\
2014 & 8 & 12 \\
2015 & 8 & 8 \\
2016 & 8 & 8 \\
\hline
\end{tabular}

This study considers all meetings that are followed by a statement. Except for three years, FOMC held eight such meetings each year between 2000 and 2016. In 2001,2007, and 2008 the members attended 11, 10, and 11 monetary policy meetings. Table 1 shows the number of FOMC meetings by year. The monetary policy statements were often brief before the financial crisis. They usually stated the interest rate decision and provided a few sentences about the economy or financial markets. After the 2008 financial crisis, the statements became longer as FOMC provided information about the unconventional monetary policy, and the committee communicated its outlook for future decisions and the state of the economy. Figure 1 shows the average number of sentences in monetary policy statements by year. Monetary policy statements are longer and potentially contain more information after the great recession.

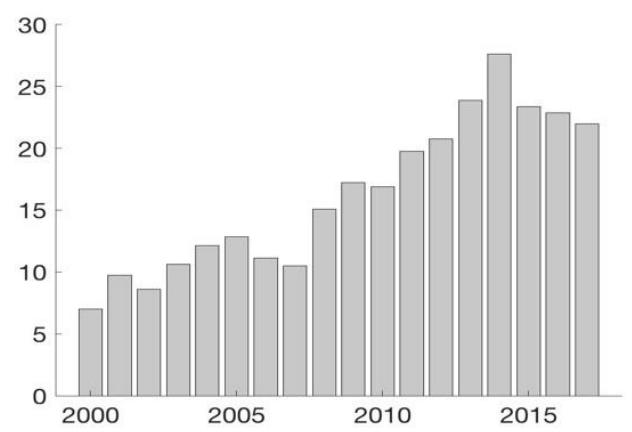

Figure 1. Average number of sentences in FOMC monetary policy statements by year

\subsection{ECB Press Conferences}

Monetary policy decisions of the European Central Bank (ECB) are made by its governing council, which consists of six members of the executive board and the governors of the national central banks of the 19 euro area countries. The governing council met once a month in most years between 2000 and 2016. Few exceptions are 2000 and 2001, in which the governing council met 24 times, and 2015 to 2016 with only eight meetings. In 2000 and 2001, 13 and 9 meetings out of 24 were followed by a press conference. From 2002 to 2005, ECB gave a press conference after 11 out of 12 meetings. Table 1 shows the number of ECB meetings by year. Before 2006, most meetings were followed by a press conference. ECB has given a press conference after every meeting since 2006. Each press conference starts with an introductory statement about the monetary policy decisions and the governing council's future outlook, followed by Q\&A. The data includes all ECB meetings that are followed by a press conference. Since the introductory statement of press conferences provide ECB's assessment of the economy and information about the current and future direction of monetary policy, the transcript of the introductory statements of press conferences is used for this study. There is no clear trend in the number of sentences of ECB introductory statements shown in Figure 2. The statements were generally longer during the financial crisis and the European debt crisis. ECB statements were longer than usual in 2000 as ECB communicated its policies through the post-meeting statements during the currency union's early years. 


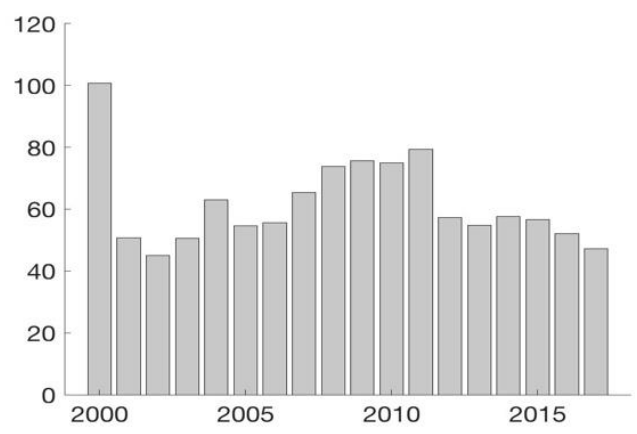

Figure 2. Average number of sentences in ECB introductory statements of monetary policy by year

\subsection{Empirical Methodology}

This section provides details of the empirical methodology used for measuring the effect of statement shocks on exchange rates. The section starts with a description of various shocks in monetary policy announcements and then explains how the impulse response of exchange rates to statement shocks and term structure shocks is estimated.

\subsubsection{Monetary Policy Shocks}

Monetary policy shocks on announcement days are broken into two parts. First, announcements that influence private sector expectations of future interest rates. Term structure shocks are defined as changes in the term structure of interest rates on announcement days. Term structure shocks indicate changes in expectations of future interest rates following the announcement of monetary policy. See Inoue and Rossi (2019) and Nakamura and Steinsson (2018). Second, announcements that affect private sector expectations of future macro fundamentals. Central banks often use post-meeting statements to communicate their current assessment of the economy and their future outlook. Statement shocks are defined as changes in the overall sentiment of monetary policy statements measured by Google's Natural Language API.

\subsubsection{Term Structure Shocks}

The announcement of monetary policy after FOMC and ECB meetings often leads to substantial changes in private sector expectations of future interest rates. The leading cause of change in interest rates on announcement days is assumed to be the announcement of monetary policy. Interest rates of different maturities change as a result of the change in expectations. Term structure shock associated with $\tau$ year(s), denoted by $\varepsilon_{t}^{T S}(\tau)$ is defined as the daily change in the yield of a zero-coupon bond that matures in $\tau$ year(s).

$$
\varepsilon_{t}^{T S}(\tau)=y_{t}(\tau)-y_{t-1}(\tau)
$$

\subsubsection{Statement Shocks}

Google offers a Natural Language API that uses pre-trained machine learning models to derive insight from unstructured text. The API uses the same machine learning technology that powers Google search to find specific answers to user questions. Sentiment analysis is one of the features of the Natural Language API that identifies the prevailing emotion within the text and determines the writer's attitude as a number between -1 and +1 . The score could then be mapped to positive, negative, and neutral categories. Natural Language API returns a sentiment score for every sentence in a given text.

Every monetary policy statement is broken into its sentences, and the sentiment score of each sentence is found using the Natural Language API. Let $N p$ represent the number of sentences in a statement that have a positive sentiment. Similarly, $\mathrm{Nn}$ and $\mathrm{Nz}$ represent the number of sentences with negative and zero sentiment scores. Sentences with a sentiment score of zero are dropped, and the share of positive sentences in the remaining sentences is recorded as the sentiment score of the statement, denoted by $v_{t}$.

$$
v_{t}=\frac{N p}{N p+N n}
$$

For illustration, suppose that a monetary policy statement has five sentences, and the sentiment score of the sentences is $0.8,0.7,0,0.2$, and -0.4 . The third sentence is excluded because it has a score of 0 . Since 3 of the four remaining sentences have a positive score, the statement's sentiment score is 0.75 . The sentiment score of a statement is a number between 0 and 1 . For a given monetary policy statement, the sentiment score of zero indicates that all sentences with non-zero scores have a negative tone, and conversely, a sentiment score of one shows that all 
sentences express a positive tone. Tables 2 and 3 show examples of positive, negative, and neutral sentences in FOMC and ECB statements.

Statement shock on announcement day $t$, denoted by $\varepsilon_{t}^{s t}$, is defined as the difference between the sentiment score of two consecutive monetary policy statements. It captures the change in the sentiment of sentences used in the statements to describe the economy's current stance and future outlook.

$$
\varepsilon_{t}^{s t}=v_{t}-v_{t-T}
$$

$T$ is the number of days between two consecutive announcement days. The sample average of statement shocks is very close to zero for both central banks. The standard deviation of the shocks is 0.10 and 0.14 for FOMC and ECB statements, respectively. Google's Natural Language API is trained using search data of millions of users. It is reasonable to assume that the Natural Language API's sentiment analysis feature measures the sentiment of statements in a way that is close to the interpretation of an average private sector agent.

Table 2. Examples of positive, negative and neutral sentences in FOMC statements

\begin{tabular}{|c|c|c|}
\hline Date & Sentence & $\begin{array}{l}\text { Sentiment } \\
\text { Score }\end{array}$ \\
\hline 2 Oct 2001 & $\begin{array}{l}\text { The terrorist attacks have significantly heightened uncertainty in an economy that was } \\
\text { already weak. }\end{array}$ & -0.6 \\
\hline 24 Jun 2009 & $\begin{array}{l}\text { Businesses are cutting back on fixed investment and staffing but appear to be making } \\
\text { progress in bringing inventory stocks into better alignment with sales. }\end{array}$ & -0.4 \\
\hline 16 Mar 2010 & $\begin{array}{l}\text { In light of improved functioning of financial markets, the Federal Reserve has been } \\
\text { closing the special liquidity facilities that it created to support markets during the } \\
\text { crisis. }\end{array}$ & 0.4 \\
\hline 28 Apr 2010 & Housing starts have edged up but remain at a depressed level. & -0.4 \\
\hline 13 Dec 2011 & $\begin{array}{l}\text { Information received since the Federal Open Market Committee met in November } \\
\text { suggests that the economy has been expanding moderately, notwithstanding some } \\
\text { apparent slowing in global growth. }\end{array}$ & 0.3 \\
\hline 19 Jun 2013 & $\begin{array}{l}\text { The Committee will closely monitor incoming information on economic and financial } \\
\text { developments in coming months. }\end{array}$ & 0 \\
\hline 17 Jun 2015 & $\begin{array}{l}\text { This assessment will take into account a wide range of information, including } \\
\text { measures of labor market conditions, indicators of inflation pressures and inflation } \\
\text { expectations, and readings on financial andobjectiv international developments. }\end{array}$ & 0.2 \\
\hline 27 Jan 2016 & $\begin{array}{l}\text { The Committee is closely monitoring global economic and financial developments } \\
\text { and is assessing their implications for the labor market and inflation, and for the } \\
\text { balance of risks to the outlook. }\end{array}$ & 0.5 \\
\hline
\end{tabular}

Table 3. Examples of positive, negative and neutral sentences in ECB statements

\begin{tabular}{llc}
\hline Date & Sentence & $\begin{array}{l}\text { Sentiment } \\
\text { Score }\end{array}$ \\
\hline 14 Sep 2000 & $\begin{array}{l}\text { In fact, recent indicators suggest that, following the period of acceleration, the } \\
\text { economic expansion may now have settled at a high rate of growth. }\end{array}$ & 0.5 \\
10 Jul 2003 & $\begin{array}{l}\text { Interest rates in the euro area are low by historical standards, both in nominal and real } \\
\text { terms, thus lending support to economic activity and helping to safeguard against } \\
\text { downside risks to economic growth. }\end{array}$ & 0.9 \\
2 Feb 2006 & $\begin{array}{l}\text { Investment is expected to remain strong, benefiting from an extended period of very } \\
\text { favourable financing conditions, balance sheet restructuring, and accumulated and } \\
\text { ongoing gains in earnings and business efficiency. }\end{array}$ & 0.7 \\
8 Feb 2007 $\begin{array}{l}\text { Turning first to the economic analysis, the latest indicators and survey data suggest } \\
\text { that the economic expansion has continued into 2007 and remains solid and } \\
\text { broad-based. }\end{array}$ & 0.6 \\
\hline
\end{tabular}


6 Dec 2012 Over the shorter term, weak activity is expected to extend into next year, reflecting and subdued foreign demand.

3 Jul 2014 Based on our regular economic and monetary analyses, we decided to keep the key ECB interest rates unchanged.

3 Sep 2015 The information available indicates a continued though somewhat weaker economic recovery and a slower increase in inflation rates compared with earlier expectations.

21 Apr 2016 At the same time, the economic recovery in the euro area is still dampened by the ongoing balance sheet adjustments in a number of sectors, the insufficient pace of implementation of structural reforms and subdued growth prospects in emerging markets.

\subsubsection{Exchange Rate Response to Statement Shocks}

Exchange rate change on announcement days is expressed as a linear function of term structure shocks and statement shock using as weights the partial derivative of the exchange rate with respect to yields and the sentiment score of statements. We have

$$
E\left(\Delta s_{t}\right)=\sum_{\tau=\tau_{1}}^{\tau_{m}} E\left(\frac{\partial \Delta s_{t}}{\partial y_{t}(\tau)}\right) \varepsilon_{t}^{T S}(\tau)+E\left(\frac{\partial \Delta s_{t}}{\partial v_{t}}\right) \varepsilon_{t}^{s t}
$$

where $s_{t}$ is the log exchange rate on day $t$ and $\Delta s_{t}=s_{t}-s_{t-1}$ is the daily change in exchange rate on announcement day $t . \tau_{1}, \ldots, \tau_{m}$ are all the maturities considered in the model.

In order to measure the response of the exchange rate to statement shocks, consider the following VAR model of the exchange rate, term structure, and statement shocks.

$$
X_{t}=\mu+B_{0}+B_{1} X_{t-1}+B_{2} X_{t-2}+u_{t}
$$

$X_{t}=\left[\Delta y_{t}(0.25) \Delta y_{t}(1) \Delta y_{t}(5) \Delta y_{t}(10) \Delta y_{t}(30) \Delta v_{t} \Delta s_{t}\right]^{\prime}$ and $E\left(u_{t} u_{t}^{\prime}\right)=\Sigma$. Estimating the VAR model identifies the transmission mechanism of monetary policy shocks to the exchange rate. $X_{t}$ could be written as a reduced-form moving average

$$
X_{t}=\zeta+u_{t}+\Theta_{1} u_{t-1}+\cdots
$$

I use the methodology of Inoue and Rossi (2019) to estimate the parameters of the VAR model and find the impulse response of exchange rates to various shocks. It is assumed that the yield curve responds to exchange rate shocks with delay. Let $A$ be the Cholesky decomposition of $\Sigma$, that is $\Sigma=A A^{\prime} . A$ and $\Theta_{h}$ could be written as four submatrices

$$
A=\left[\begin{array}{cc}
A_{11} & 0 \\
A_{21} & a_{22}
\end{array}\right]
$$

and

$$
\Theta_{h}=\left[\begin{array}{cc}
\Theta_{11, h} & 0 \\
\Theta_{21, h} & \theta_{22, h}
\end{array}\right]
$$

where $A_{11}$ and $\Theta_{11, h}$ are $(m+1) \times(m+1), A_{21}$ and $\Theta_{21, h}$ are $1 \times(m+1)$ and $a_{22}$ and $\theta_{22, h}$ are scalers. $m$ is the number of maturities considered for measuring term structure shocks in the VAR model. Since I include interest rate changes of five maturities in the VAR model, $m=5$.

The partial derivative of the exchange rate with respect to yields and the sentiment of statements can be written as

$$
\Theta_{21, h}+\theta_{22, h} A_{21} A_{11}^{-1}
$$

Let $\varepsilon_{t}^{m p}$ be the vector of monetary policy shocks on announcement day $t . \varepsilon_{t}^{m p}$ is comprised of term structure shocks and statement shock.

$$
\varepsilon_{t}^{m p}=\left[\begin{array}{ll}
\varepsilon_{t}^{T S} & \varepsilon_{t}^{s t}
\end{array}\right]^{\prime}
$$

where $\varepsilon_{t}^{T S}$ is the vector of shocks to the term structure of interest rates and

$$
\varepsilon_{t}^{T S}=\left[\varepsilon_{t}^{T S}(0.25) \varepsilon_{t}^{T S}(1) \varepsilon_{t}^{T S}(5) \varepsilon_{t}^{T S}(10) \varepsilon_{t}^{T S}(30)\right]^{\prime} .
$$

The impulse response of the exchange rate to monetary policy shocks $\varepsilon_{t}^{m p}$ is 


$$
\Delta_{h}=\left(\Theta_{21, h}+\theta_{22, h} A_{21} A_{11}^{-1}\right) \varepsilon_{t}^{m p}
$$

where $\Delta_{h}$ is $(m+1) \times 1$. The first $m$ elements of $\Delta_{h}$ are the contribution of term structure shocks to the impulse response after $h$ periods and the last element is the effect of statement shock on the exchange rate in $h$ periods.

It should be noted that the results rest on several assumptions about the model. For instance, the assumption of delayed response of yield curve to exchange rate shocks is necessary to estimate the VAR model. Another implicit assumption is that the model can separate the effect of term structure and statement shocks. While these assumptions are common in the literature, one might argue that reliance on these assumptions is a limitation of the method used in this paper.

\section{Results}

Figure 3 shows the impulse response of dollar exchange rates to positive and negative FOMC statement shocks. The top charts of Figure 3 demonstrate the impulse response of dollar vis-à-vis euro, pound, and yen to positive statement shocks, and the bottom charts indicate the impulse responses to negative statement shocks. Figure 3 shows that the U.S. dollar depreciates (appreciates) following a positive (negative) statement shock. In other words, investors sell the dollar when the FOMC statement contains more positive sentences than the previous one. This market reaction is puzzling because one would expect the currency to appreciate in response to a more optimistic statement. The negative relation between the value of the dollar and the sentiment of monetary policy statements could be explained by the sizeable effect of U.S. monetary policy on other countries' macroeconomic fundamentals and financial markets. Maćkowiak (2007) shows that the price level and real output in a typical emerging market respond to U.S. monetary policy shocks by more than the price level and real output in the U.S. itself. Kim (2001) is another study that focuses on the international transmission effect of U.S. monetary policy through various channels. When FOMC releases a more positive statement than its previous statement, private sector agents raise their expectations of U.S. economic fundamentals, but they raise their expectations of fundamentals in other countries even more. Therefore, the U.S. dollar depreciates relative to other major currencies. Another explanation for this negative relationship is the special status of the U.S. dollar as the safe-haven currency. Investors tend to sell the dollar and buy riskier currencies when FOMC members have a positive outlook for the U.S. and global economy. When the statement is more negative than the previous one, investors sell other currencies and buy the dollar. Suppose we accept that international spillover of U.S. monetary policy or the safe-haven status of the U.S. dollar explains the negative relationship between statement shocks and dollar exchange rates. In that case, there should be a positive relationship between the sentiment of ECB statements and euro exchange rates because the international spillover effect of ECB policies to countries outside the eurozone is relatively limited. Fratzscher, Duca, and Straub (2016) study the regional and international effect of unconventional ECB policies and show limited evidence of portfolio rebalancing across regions and assets on impact. Moreover, the euro is not considered a safe-haven currency. Figure 4 shows that there is indeed a positive relationship between ECB statement shocks and the euro's value relative to other currencies. Positive statement shocks lead to an appreciation of the euro vis-à-vis other major currencies, and negative shocks cause the euro to depreciate. 


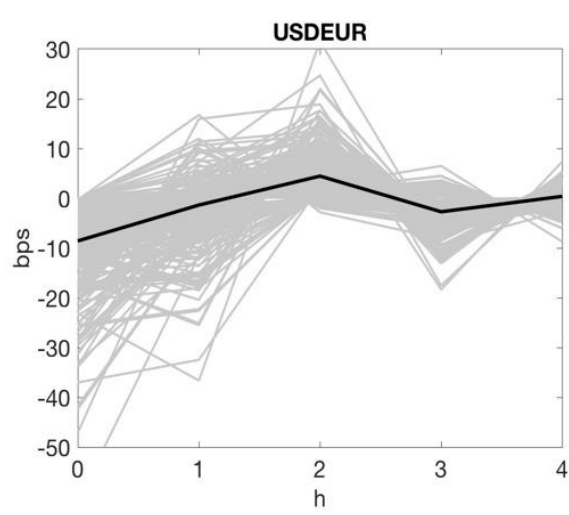

(a) $\varepsilon_{t}^{s t}>0$

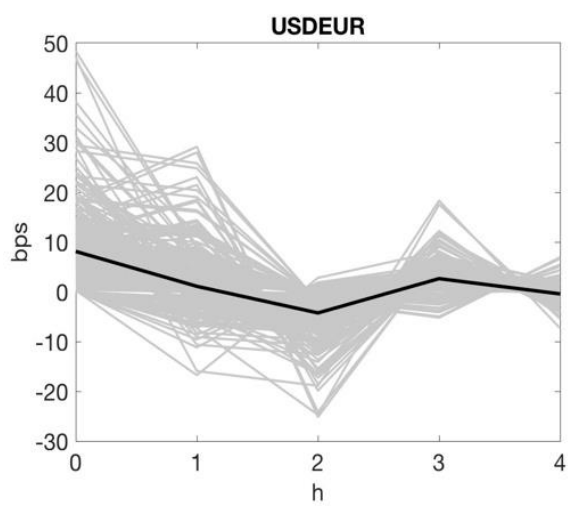

(d) $\varepsilon_{t}^{s t}<0$

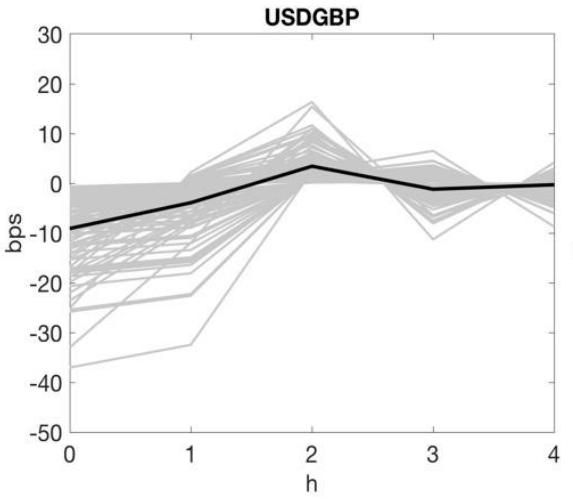

(b) $\varepsilon_{t}^{s t}>0$

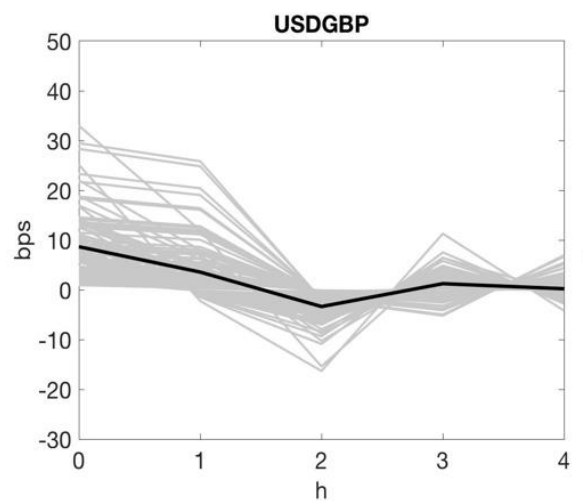

(e) $\varepsilon_{t}^{s t}<0$

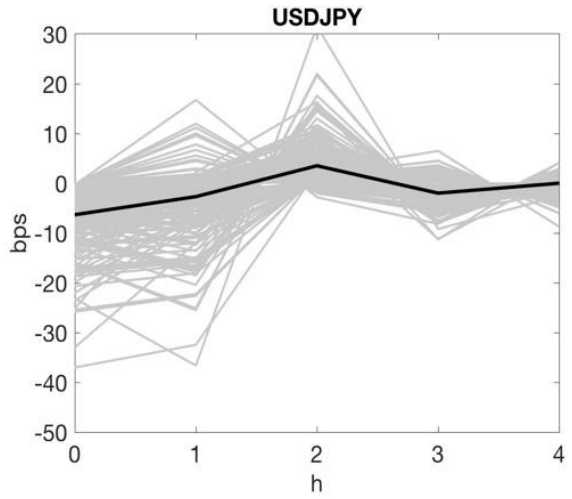

(c) $\varepsilon_{t}^{s t}>0$

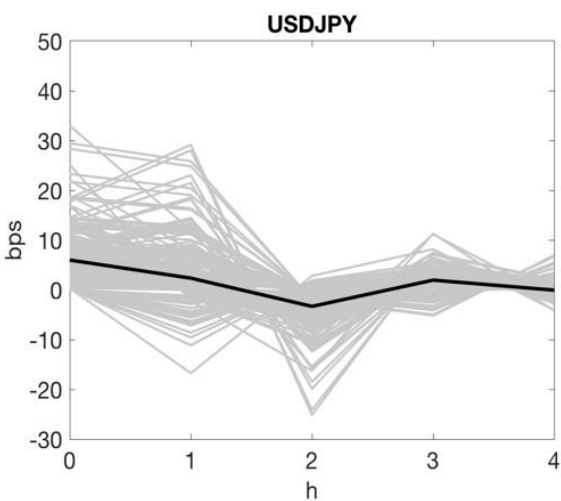

(f) $\varepsilon_{t}^{s t}<0$

Figure 3. Response of U.S. Dollar exchange rates to positive and negative statement shocks

Description: Each gray line in the figures indicates the response of the exchange rate to a statement shock. The black lines show the response of the exchange rate to an average shock. (a), (b), and (c) provide the exchange rate response to positive statement shocks, and (d), (e), and (f) depict the exchange rate response to negative statement shocks. 


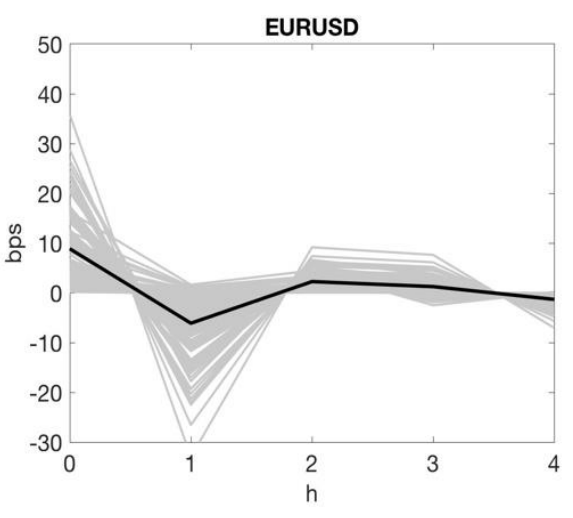

(a) $\varepsilon_{t}^{s t}>0$

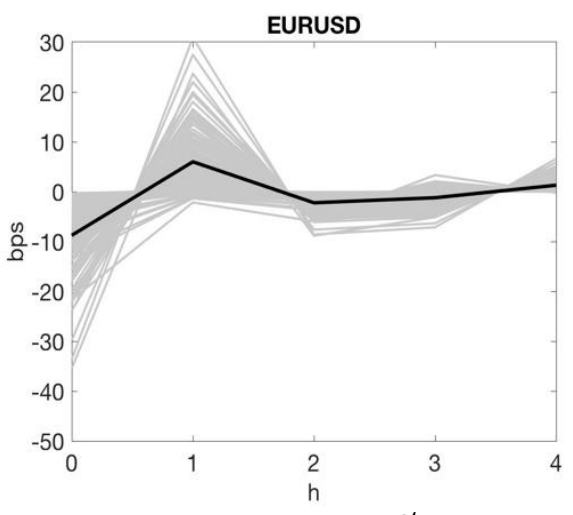

(d) $\varepsilon_{t}^{s t}<0$

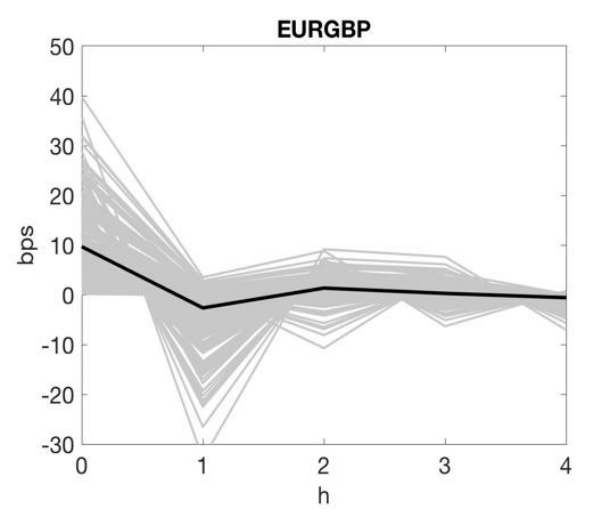

(b) $\varepsilon_{t}^{s t}>0$

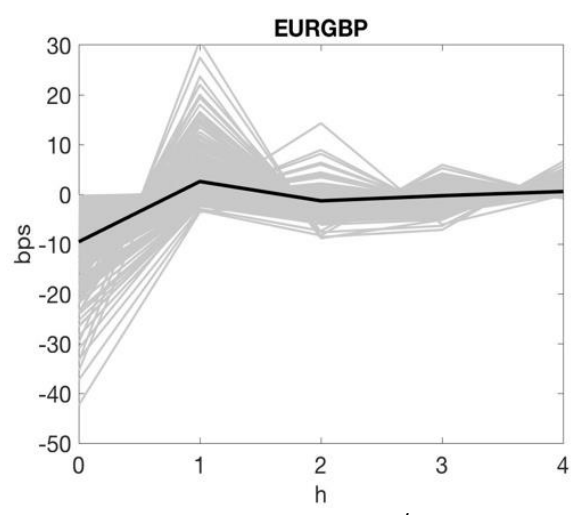

(e) $\varepsilon_{t}^{s t}<0$

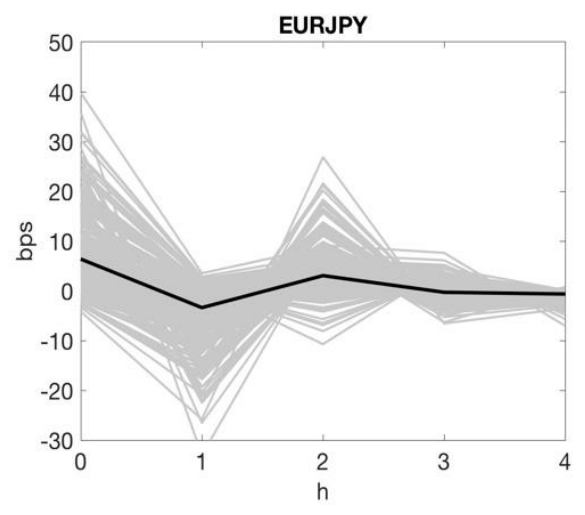

(c) $\varepsilon_{t}^{s t}>0$

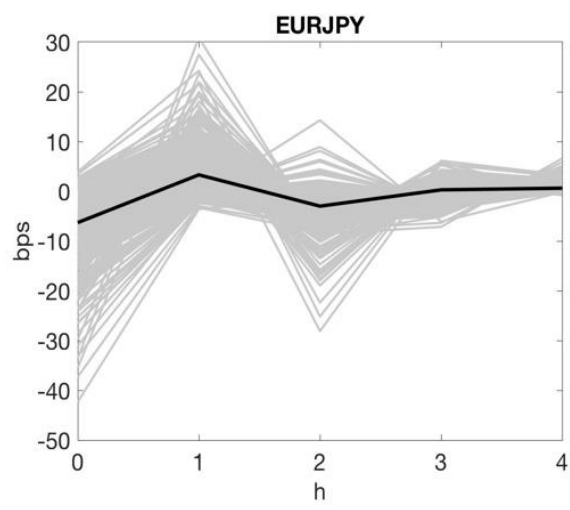

(f) $\varepsilon_{t}^{s t}<0$

Figure 4. Response of Euro exchange rates to positive and negative statement shocks

\subsection{Effect of Statement Shocks in Conventional and Unconventional Times}

This section investigates the effect of statement shocks on exchange rates during periods of conventional and unconventional monetary policy. The goal is to determine whether the effect of statement shocks is different when the central bank reaches the zero lower bound.

In general, the term "conventional times" refers to times when the short-term interest rate is the primary monetary policy tool. Central banks use "unconventional" policy tools such as quantitative easing and forward guidance when the short-term interest rate is zero. The sample is broken into two sub-periods of conventional from January 2000 to November 2008 and unconventional from November 2008 to June 2016. The same sub-periods are considered to investigate the effect of FOMC and ECB statement shocks. The VAR model is estimated separately for the sub-periods and the two major central banks across various exchange rates. The idea is that the structural transmission of monetary policy shocks to exchange rates might be different during conventional and unconventional times. Figures 5 and 6 show the impulse response of dollar exchange rates to FOMC statement shocks in conventional and unconventional times. The figures indicate that the negative relation between FOMC statement shocks and the dollar's value is not specific to conventional or unconventional periods. Figures 7 and 8 provide impulse response of euro exchange rates to ECB statement shocks during the conventional and unconventional sub-periods. The figures demonstrate the positive relation between ECB statement shocks and the euro's value in both sub-periods. 


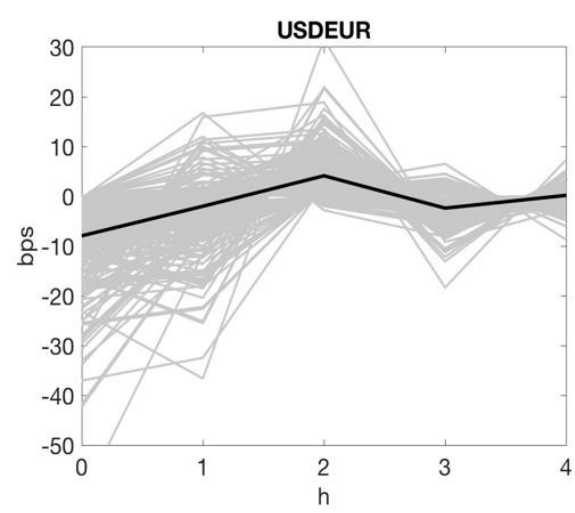

(a) $\varepsilon_{t}^{s t}>0$

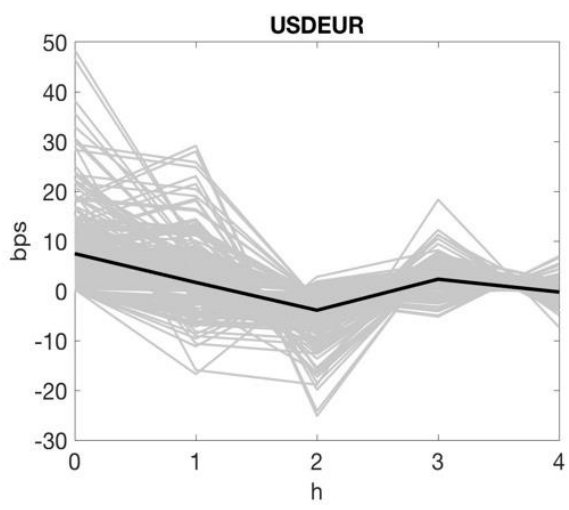

(d) $\varepsilon_{t}^{s t}<0$

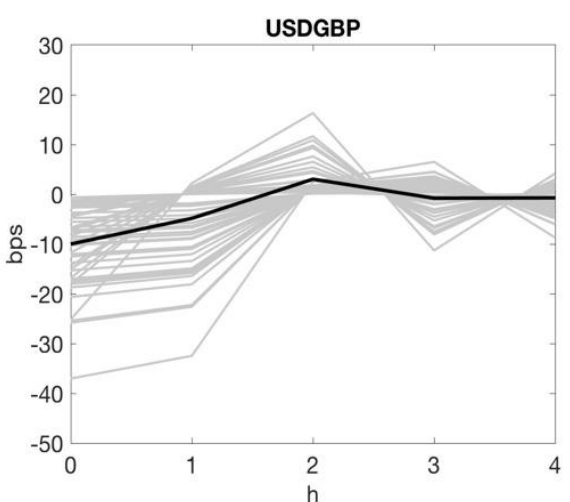

(b) $\varepsilon_{t}^{s t}>0$

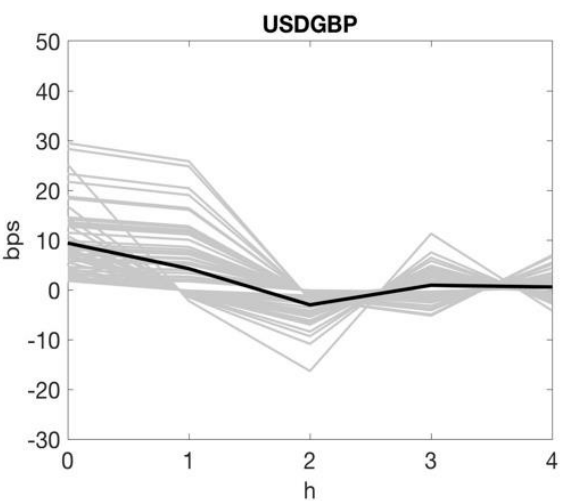

(e) $\varepsilon_{t}^{s t}<0$

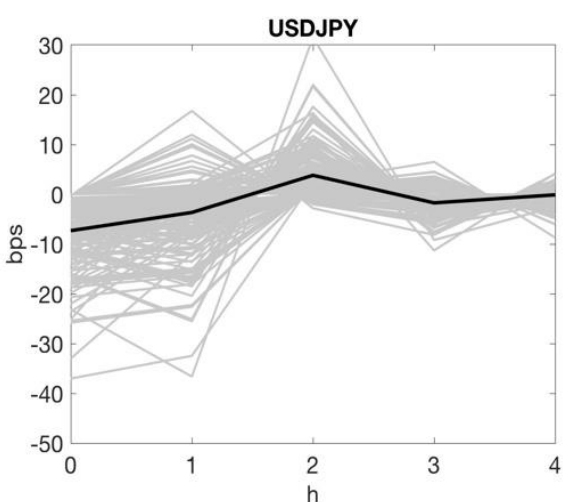

(c) $\varepsilon_{t}^{s t}>0$

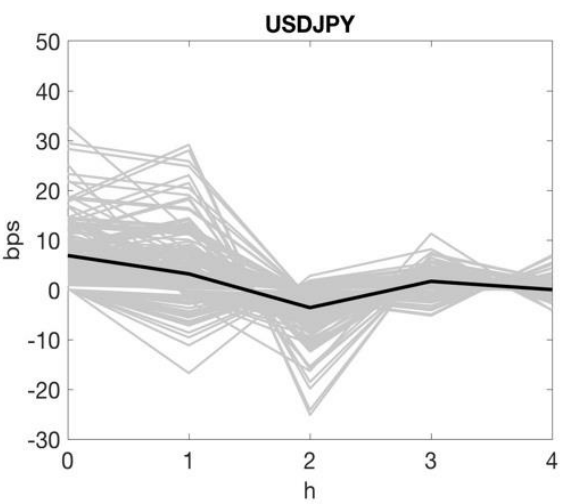

(f) $\varepsilon_{t}^{s t}<0$

Figure 5. Response of U.S. Dollar exchange rates to statement shocks: Conventional policy period (2000m1-2008m11) 


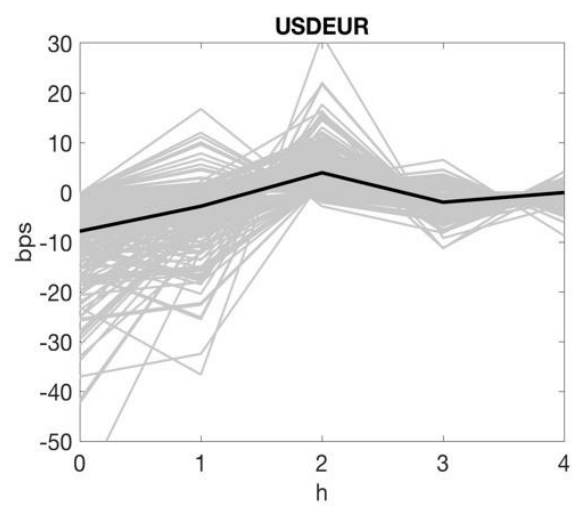

(a) $\varepsilon_{t}^{s t}>0$

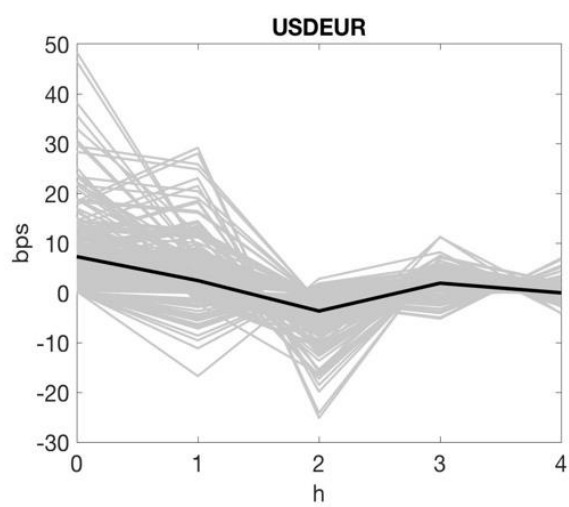

(d) $\varepsilon_{t}^{s t}<0$

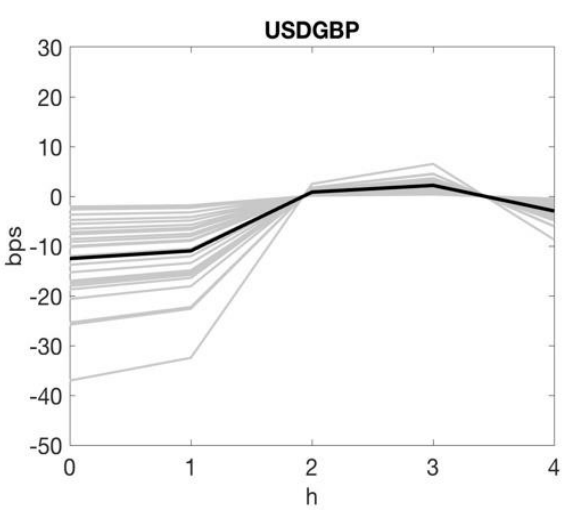

(b) $\varepsilon_{t}^{s t}>0$

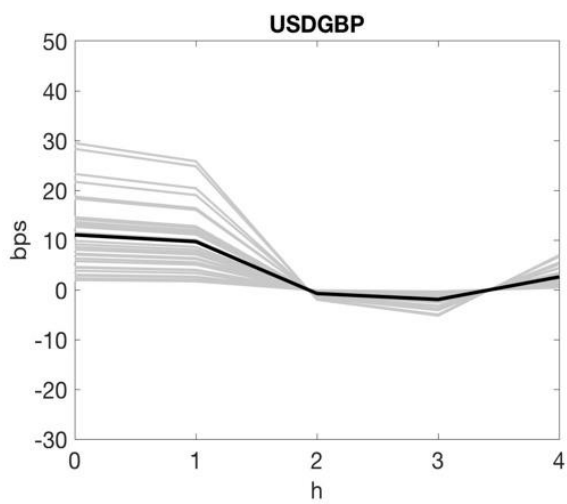

(e) $\varepsilon_{t}^{s t}<0$

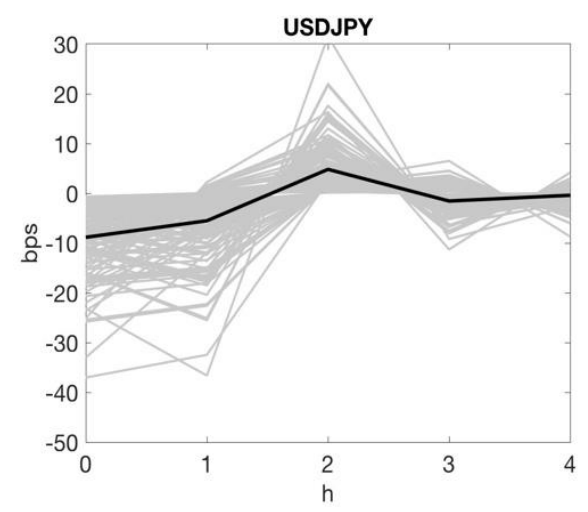

(c) $\varepsilon_{t}^{s t}>0$

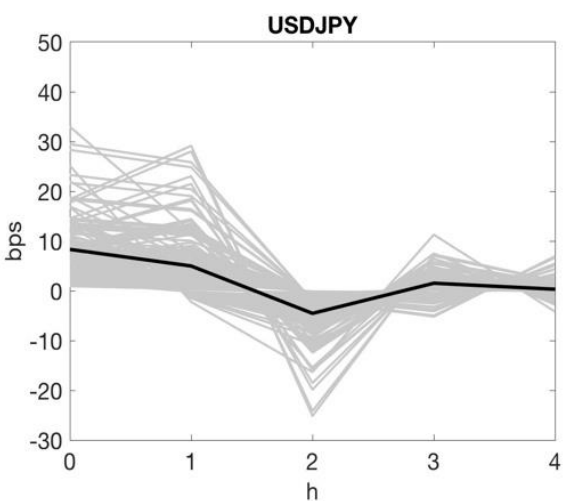

(f) $\varepsilon_{t}^{s t}<0$

Figure 6. Response of U.S. Dollar exchange rates to statement shocks:Unconventional policy period (2008m11-2016m6) 

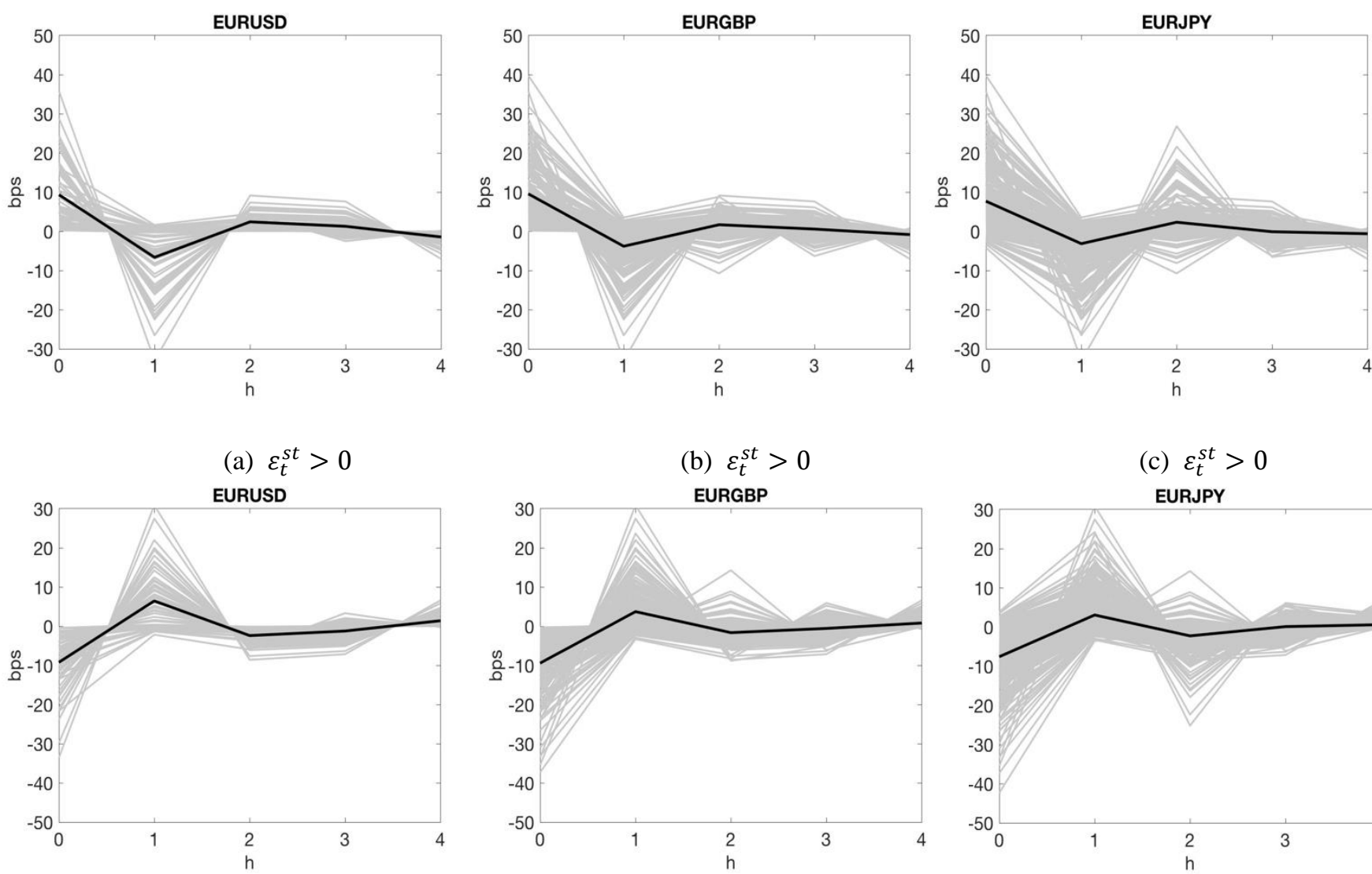

(b) $\varepsilon_{t}^{s t}>0$

(c) $\varepsilon_{t}^{s t}>0$

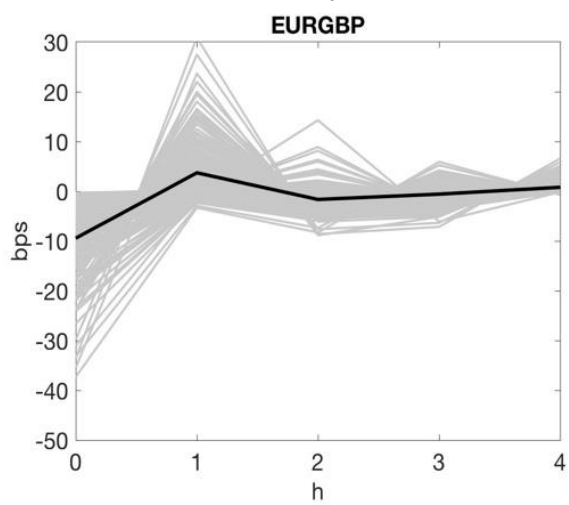

(d) $\varepsilon_{t}^{s t}<0$

(e) $\varepsilon_{t}^{s t}<0$

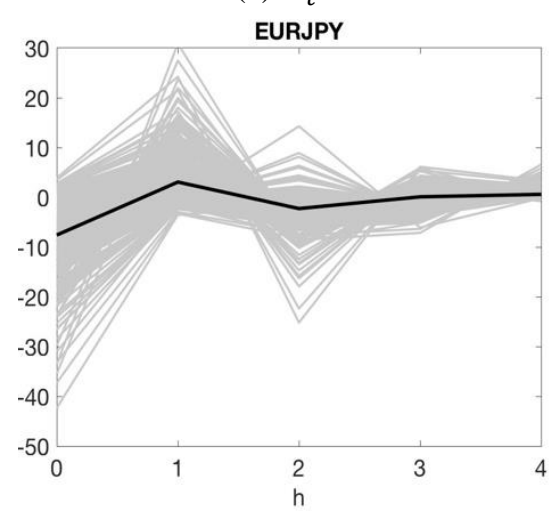

(f) $\varepsilon_{t}^{s t}<0$

Figure 7. Response of Euro exchange rates to statement shocks: Conventional policy period (2000m1-2008m11) 

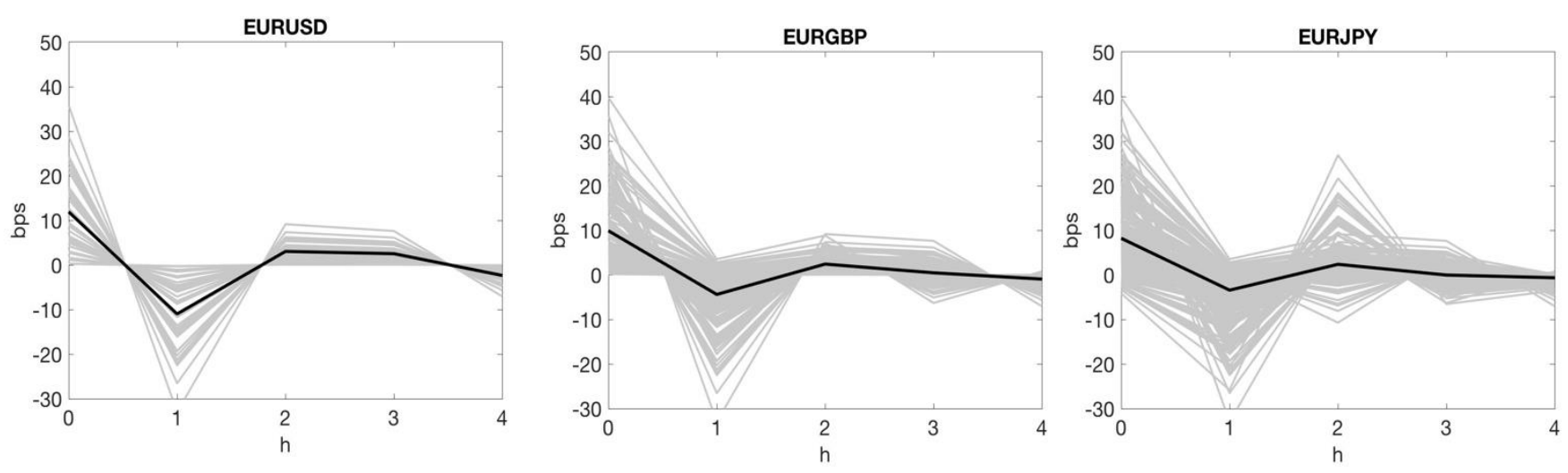

(a) $\varepsilon_{t}^{s t}>0$

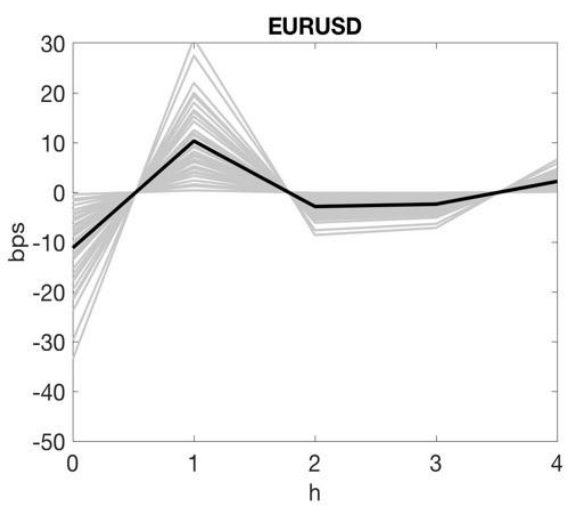

(d) $\varepsilon_{t}^{s t}<0$ (b) $\varepsilon_{t}^{s t}>0$

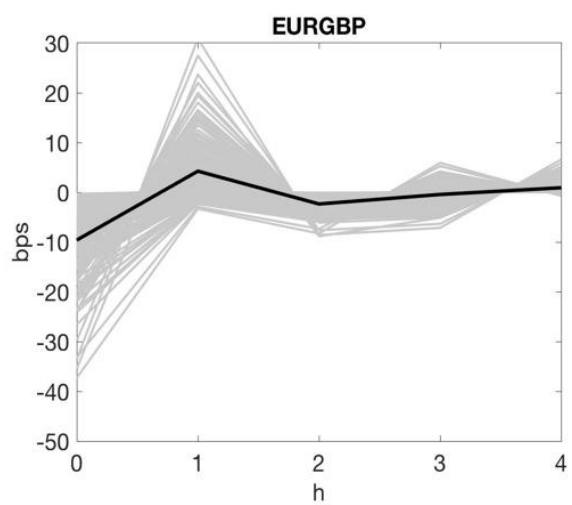

(e) $\varepsilon_{t}^{s t}<0$ (c) $\varepsilon_{t}^{s t}>0$

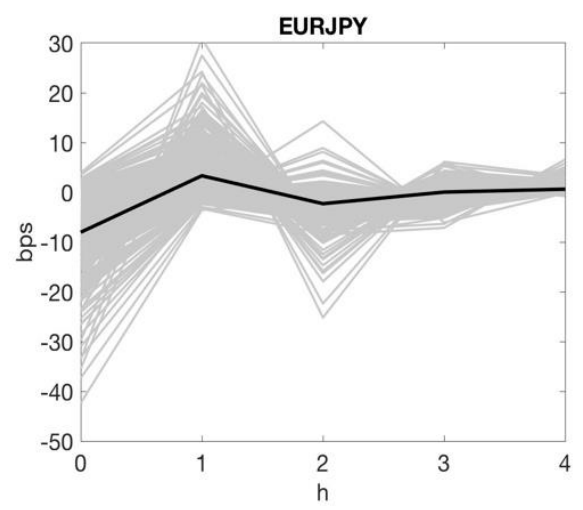

(f) $\varepsilon_{t}^{s t}<0$

Figure 8. Response of Euro exchange rates to statement shocks:Unconventional policy period (2008m11-2016m6)

In summary, the results of section 3 are not driven by conventional or unconventional times. Moreover, the size of the exchange rate impulse response is not materially different in the sub-periods.

\subsection{Effect of Statement Shocks after Expansionary and Contractionary Policy Announcements}

Monetary policy announcements often lead to significant changes in interest rates of various maturities. The change in interest rates reflect changes in expectations of future interest rate after the announcements. This section examines the effect of statement shocks on exchange rates after the announcement of expansionary and contractionary monetary policies. The goal is to determine if the effect of statement shocks on exchange rates depends on the type of policy announced by the central bank.

I classify every meeting as contractionary or expansionary based on the change in the five-year interest rate on the announcement day. For a given monetary policy meeting, the announcement is labeled contractionary if $\varepsilon_{t}^{T S}(5)>0$ and expansionary if $\varepsilon_{t}^{T S}(5)<0$. I chose the change in the five-year interest rate to classify policy announcements because the five-year rate represents the expectations of the medium-term interest rate. Moreover, short-term interest rates are zero during half of the sample. It is shown later that the choice of maturity for identifying contractionary and expansionary announcements is not critical to the results. Figures 9 and 10 show the impulse response of dollar exchange rates to FOMC statement shocks after contractionary and expansionary announcements, respectively. Panel (a) of Figures 9 and 10 show the entire term structure's response to expansionary and contractionary shocks. When FOMC announces an expansionary monetary policy, the yield curve shifts down, and conversely, the entire yield curve shifts up when FOMC announces a contractionary policy. The choice of a particular maturity for identifying expansionary and contractionary policies is not essential. Panels (b)-(g) of Figures 9 and 10 show that the negative relationship between statement shocks and the value of the dollar does not depend on the type of monetary policy announced after FOMC meetings. Figures 11 and 12 show the results for ECB statement shocks and euro exchange rates after expansionary and contractionary announcements. Like the FOMC results, separating the statements based on the type of monetary policy announcement does little to change the positive relation between ECB statement shocks and the value of the euro vis-à-vis other major currencies. 


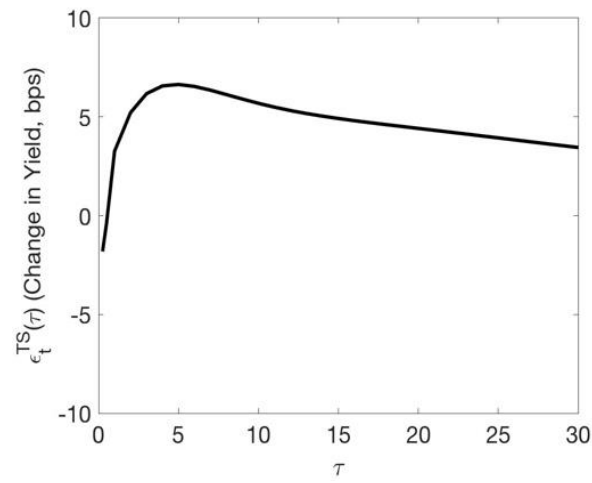

(a)

(b) $\varepsilon_{t}^{s t}>0$
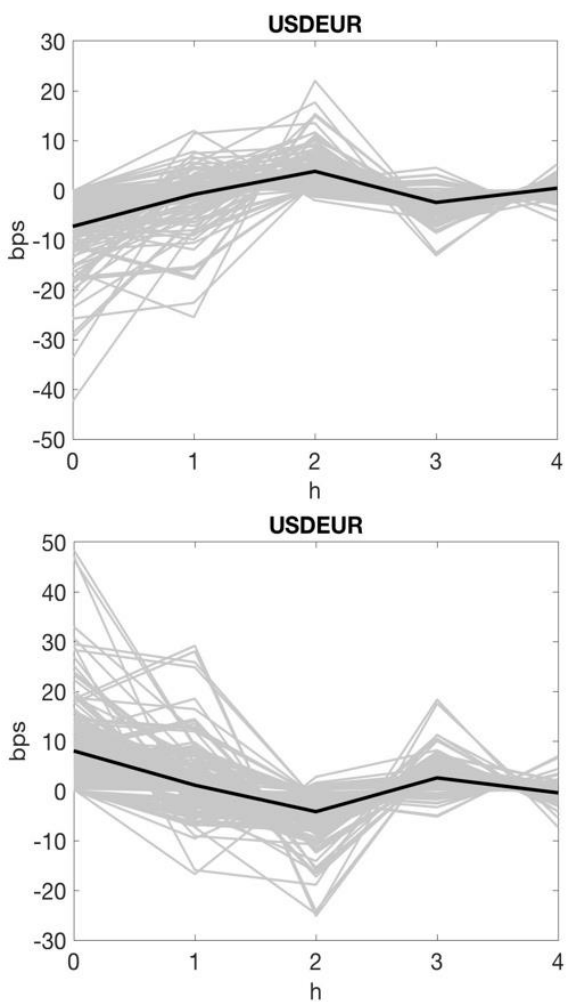

(e) $\varepsilon_{t}^{s t}<0$ (c) $\varepsilon_{t}^{s t}>0$

(d) $\varepsilon_{t}^{s t}>0$
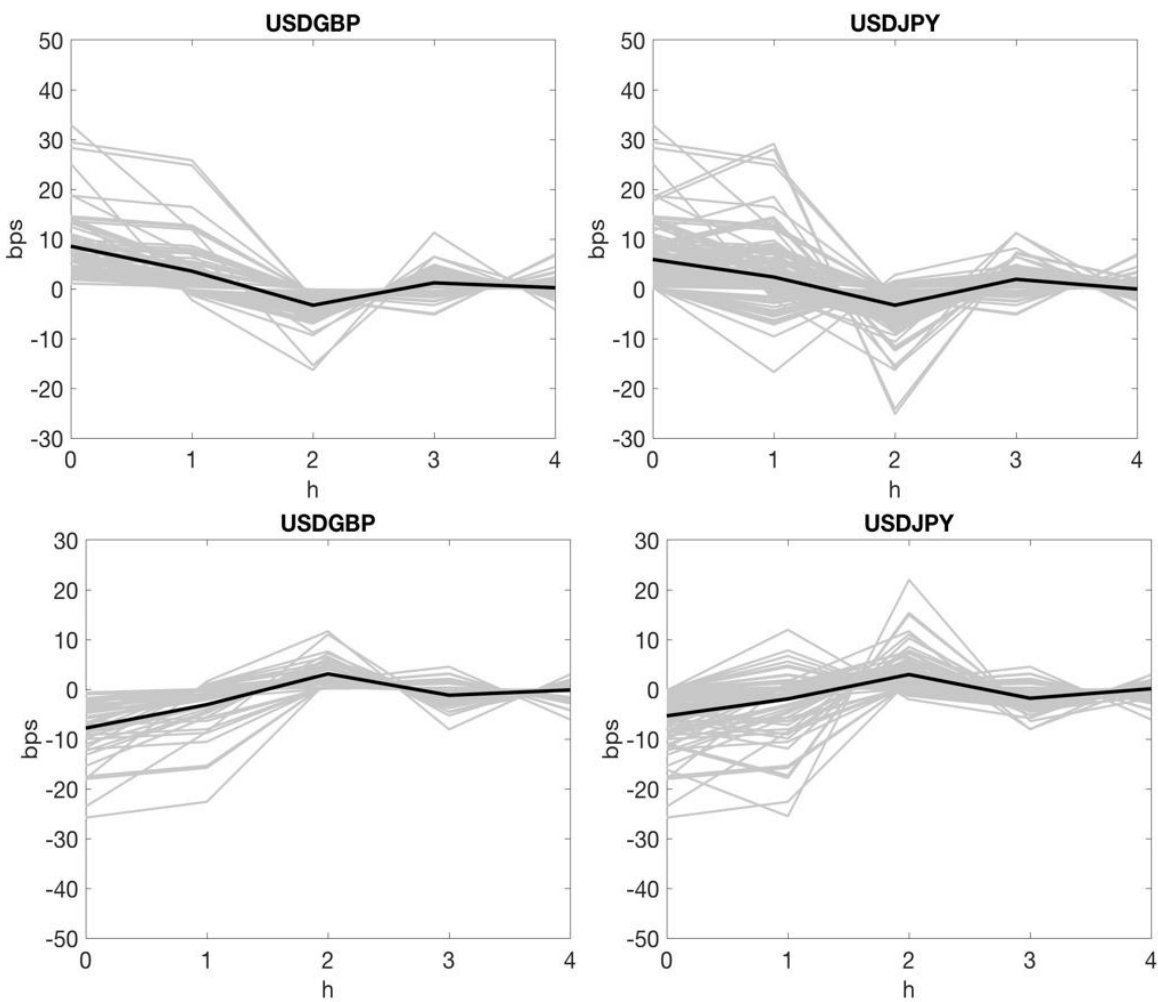

(f) $\varepsilon_{t}^{s t}<0$

(g) $\varepsilon_{t}^{s t}<0$

Figure 9. Response of U.S. Dollar exchange rates to statement shocks when FOMC announces a contractionary policy 


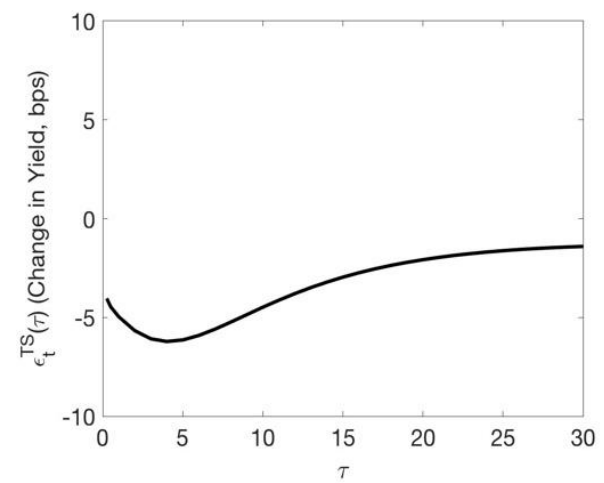

(a)
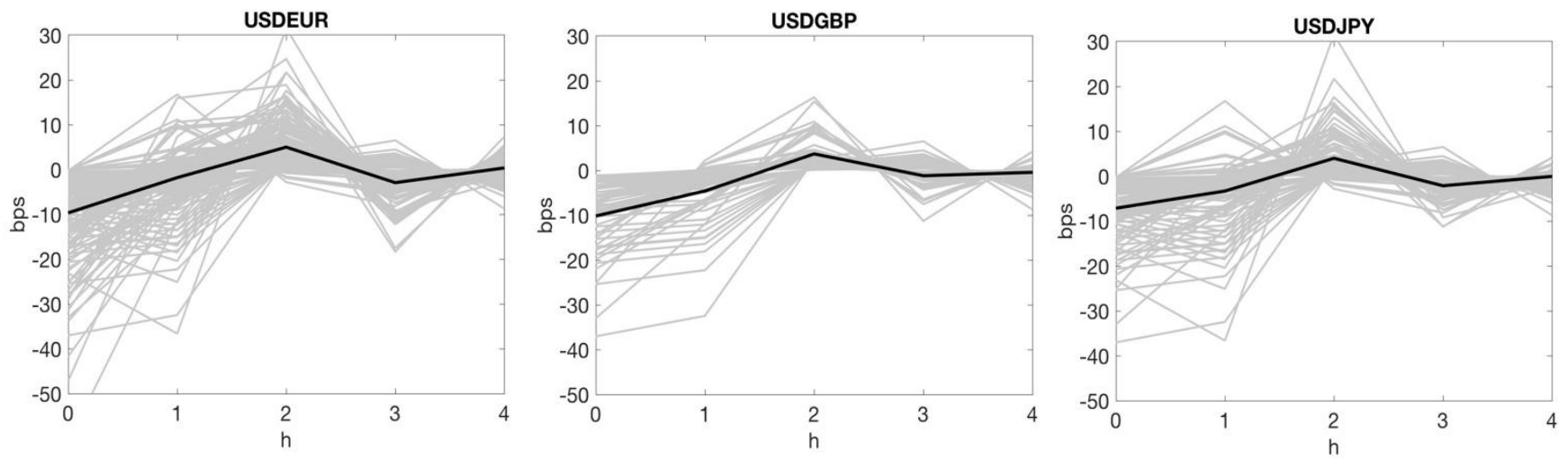

(b) $\varepsilon_{t}^{s t}>0$

(c) $\varepsilon_{t}^{s t}>0$

(d) $\varepsilon_{t}^{s t}>0$
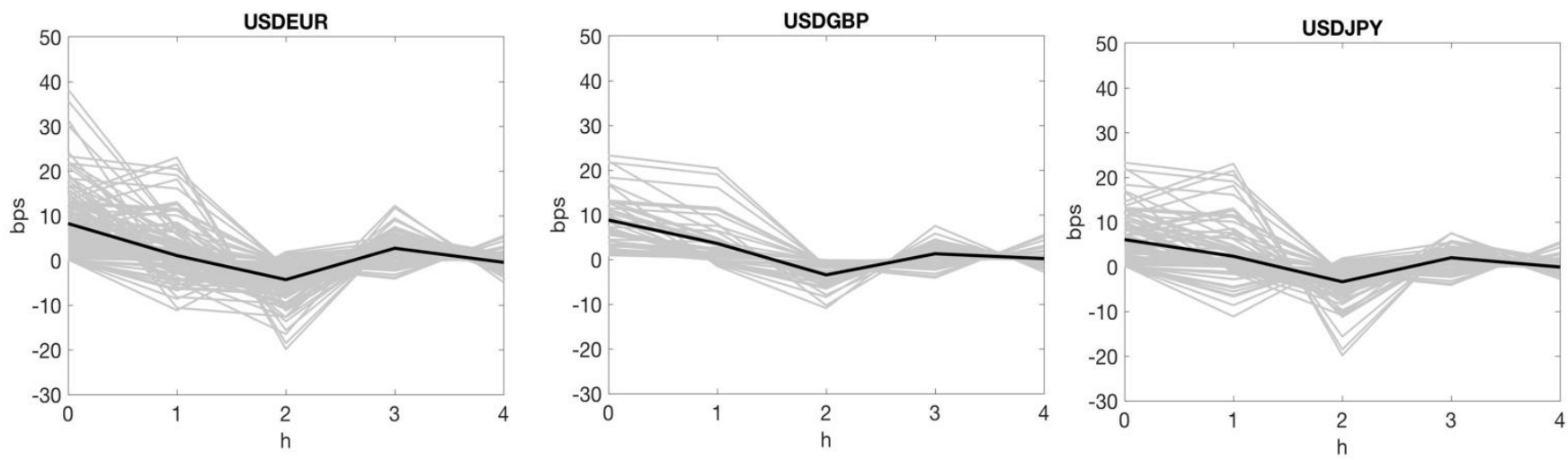

(e) $\varepsilon_{t}^{s t}<0$

(f) $\varepsilon_{t}^{s t}<0$

(g) $\varepsilon_{t}^{s t}<0$

Figure 10. Response of U.S. Dollar exchange rates to statement shocks when FOMC announces an expansionary policy 


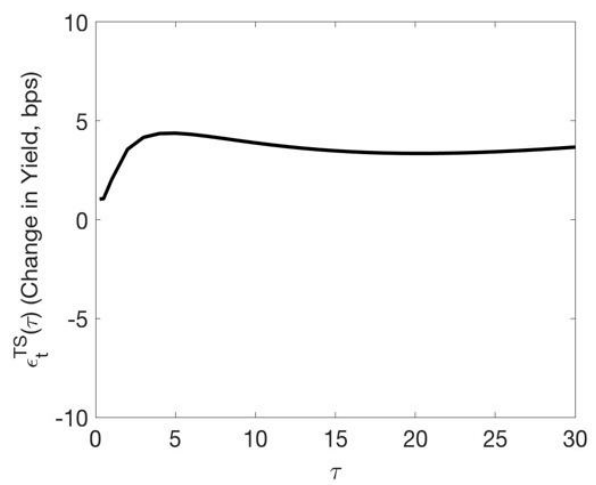

(a)

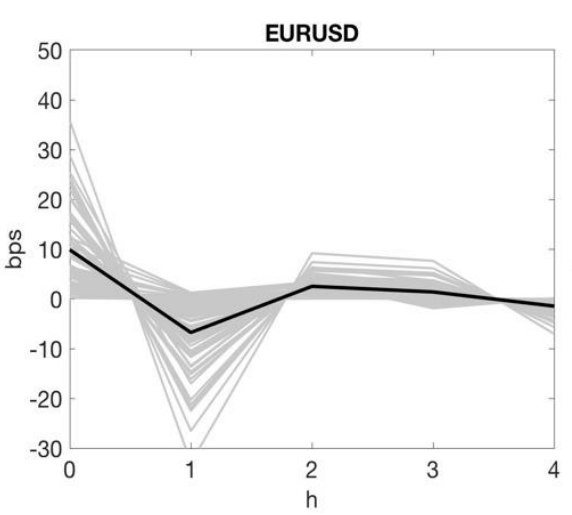

(b) $\varepsilon_{t}^{s t}>0$

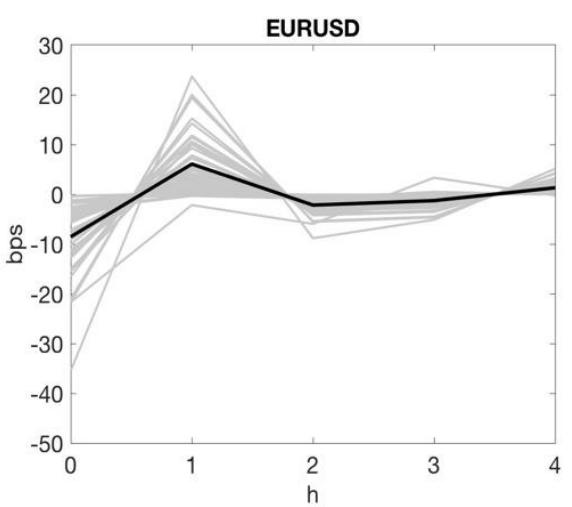

(e) $\varepsilon_{t}^{s t}<0$

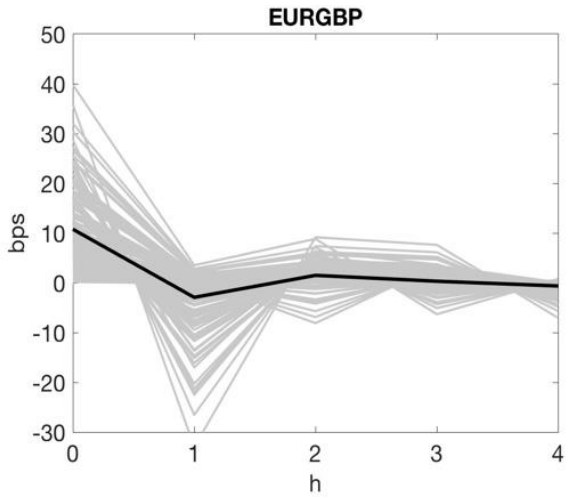

(c) $\varepsilon_{t}^{s t}>0$

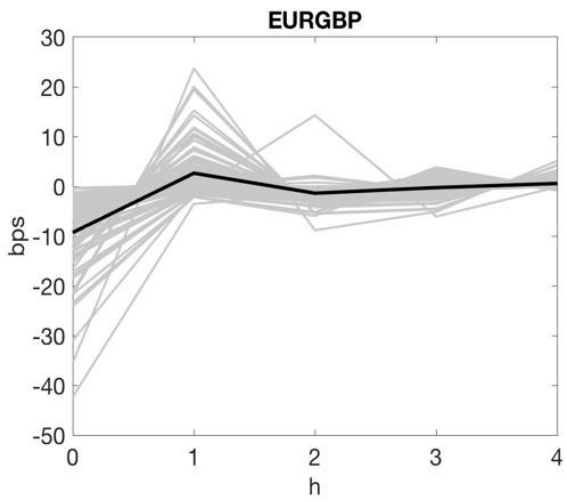

(f) $\varepsilon_{t}^{s t}<0$

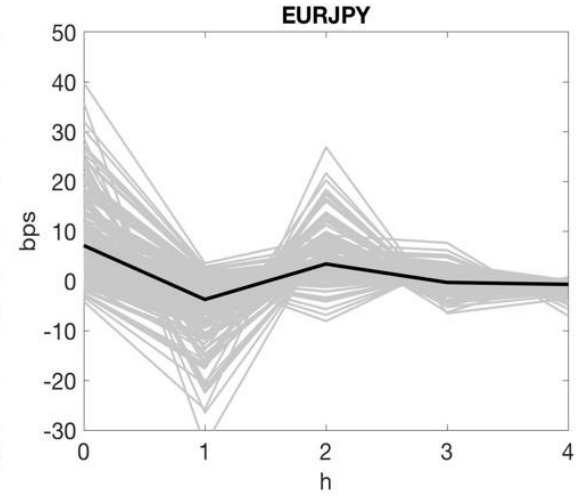

(d) $\varepsilon_{t}^{s t}>0$

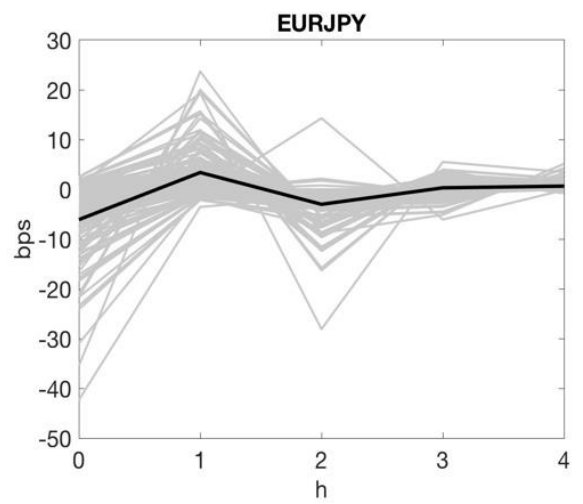

(g) $\varepsilon_{t}^{s t}<0$

Figure 11. Response of Euro exchange rates to statement shocks when ECB announces a contractionary policy 


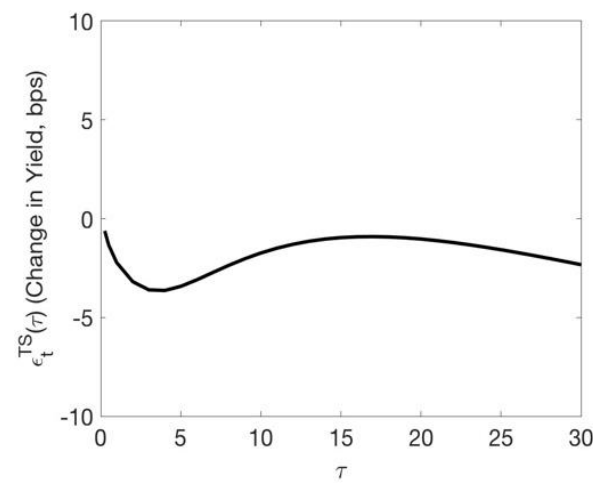

(a)

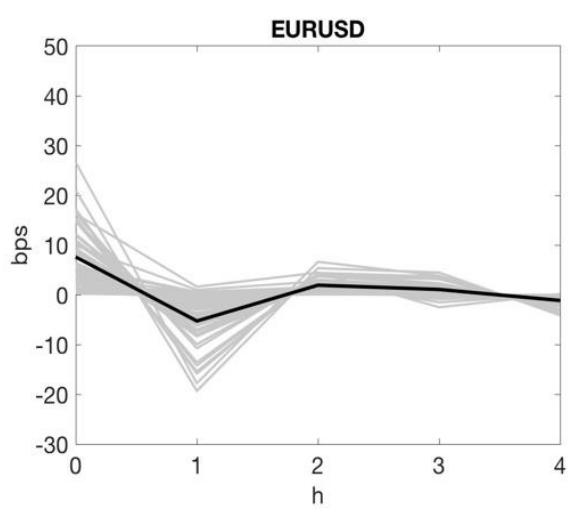

(b) $\varepsilon_{t}^{s t}>0$

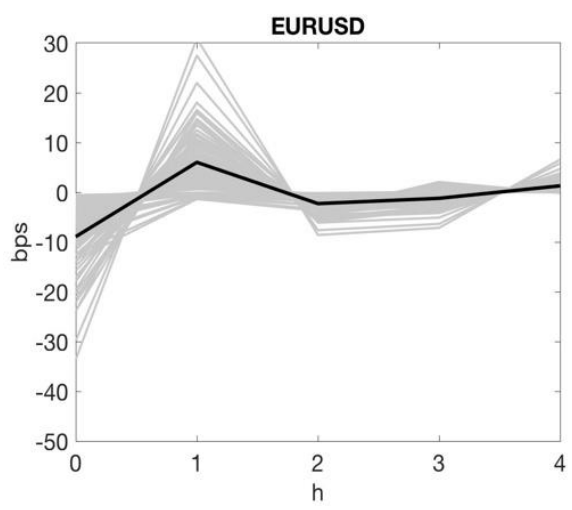

(e) $\varepsilon_{t}^{s t}<0$

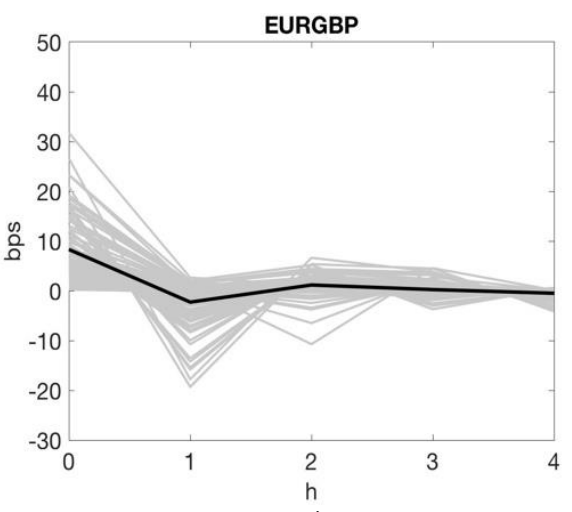

(c) $\varepsilon_{t}^{s t}>0$

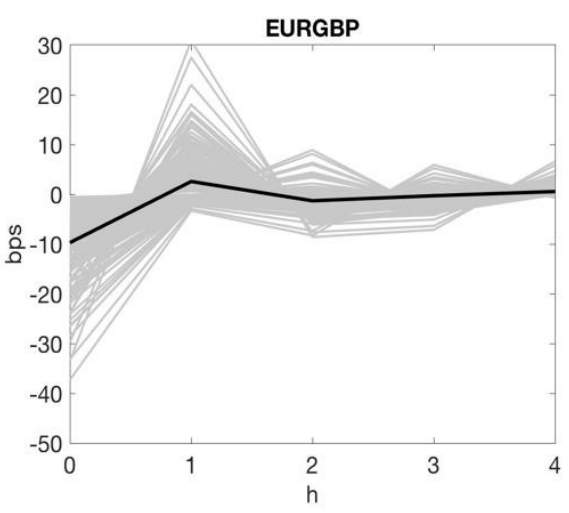

(f) $\varepsilon_{t}^{s t}<0$

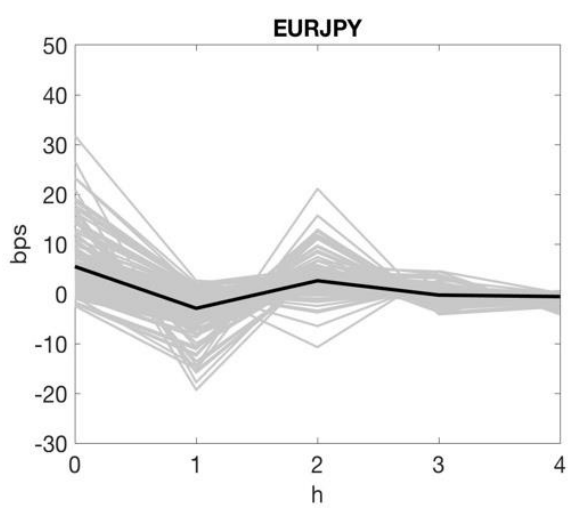

(d) $\varepsilon_{t}^{s t}>0$

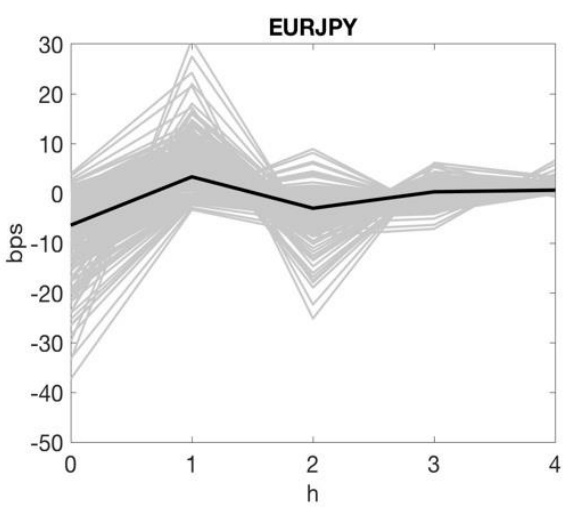

(g) $\varepsilon_{t}^{s t}<0$

Figure 12. Response of Euro exchange rates to statement shocks when ECB announces an expansionary policy

\subsection{Information Channel}

FOMC members provide their forecast of some key economic indicators after monetary policy announcements. If market participants believe that central bank officials possess superior information about the economy, they update their expectations following a change in the Fed's economic indicators forecast. Investors express their updated expectations through order flow, which leads to a change in exchange rates. See Evans and Lyons (2002) and Guo (2017). One might argue that revisions to Fed forecasts are the primary driver of exchange rate changes on announcement days. To control for the effect of Fed forecasts, monetary policy shocks $\varepsilon_{t}^{m p}$ are regressed on the Fed forecasts, and the residual of the regression is used to estimate the VAR model and find the impulse response of the 
exchange rates to statement shocks. Green Book forecasts of economic activity indicators are obtained from the Federal Reserve website and included in the following regression. The independent variables are the forecasts and revisions to the forecasts.

$$
\varepsilon_{t}^{m p}=\beta F_{t}^{t+1}+\gamma\left(F_{t}^{t+1}-F_{t-1}^{t+1}\right)+\eta_{t}^{m p}
$$

where $F_{t}^{t+1}$ is the vector of central bank forecasts made at time $t$ for next period real output growth, inflation, and unemployment. $\eta_{t}^{m p}$ is the vector of residuals from the regression. $\eta_{t}^{m p}$ is used to estimate the VAR model and measure the effect of statement shocks on exchange rates. Figure 13 demonstrates that the effect of statement shocks remains mostly intact when we control for the effect of central bank forecasts. The limited impact of Fed forecasts on exchange rates compared to that of statements could be explained by the fact that Fed forecasts provide expectations of central bankers for some near-term U.S. macro indicators. In contrast, the statements provide information about the Fed's expectations of medium to long-run domestic fundamentals and their global growth outlook. Section 4 discusses the effect of statements through the information channel in more detail.

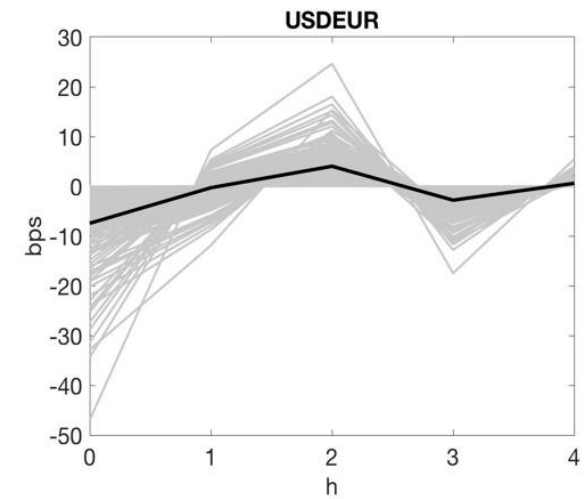

(a) $\varepsilon_{t}^{s t}>0$

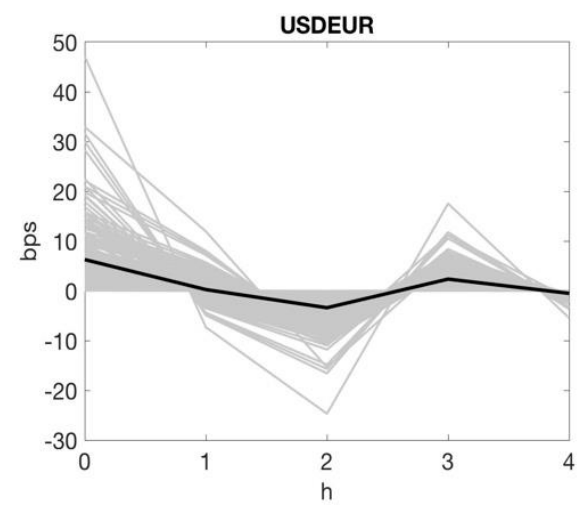

(d) $\varepsilon_{t}^{s t}<0$

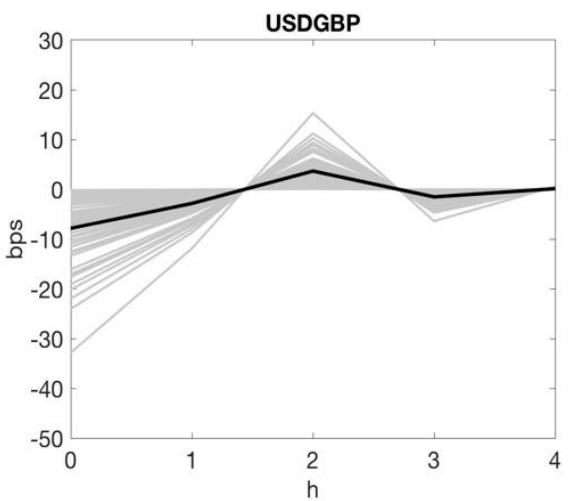

(b) $\varepsilon_{t}^{s t}>0$

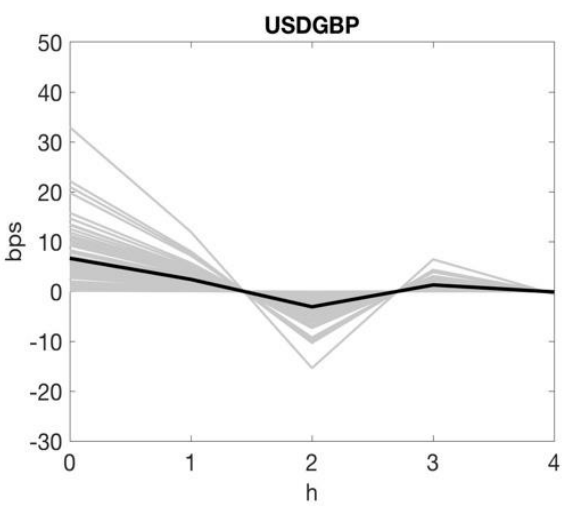

(e) $\varepsilon_{t}^{s t}<0$

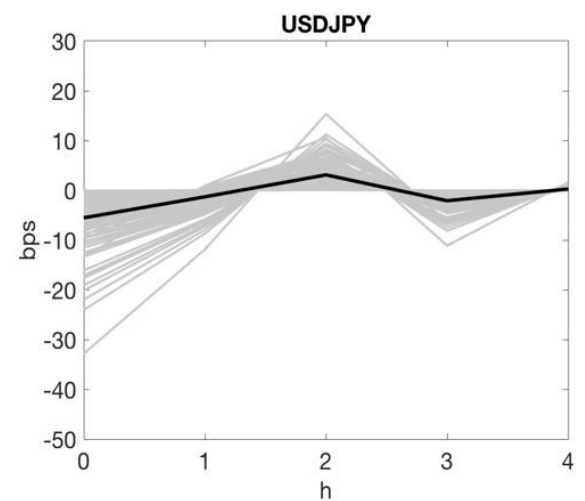

(c) $\varepsilon_{t}^{s t}>0$

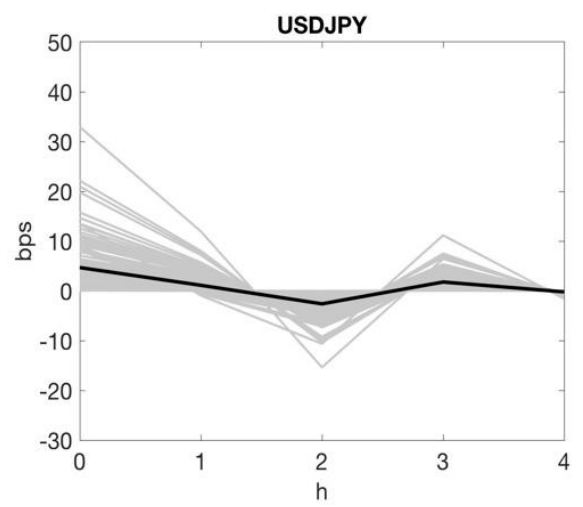

(f) $\varepsilon_{t}^{s t}<0$

Figure 13. Response of U.S. Dollar exchange rates to statement shocks after controlling for the effect of Fed forecasts

\subsection{Effect of Fed Chair Press Conferences}

Some FOMC meetings are followed by a press conference where the chair reads a statement and responds to reporters' questions. To verify the robustness of the results, I measure shocks to the introductory statement of Fed chair press conferences and include them in the main VAR model. More specifically, I estimate the following model and report the impulse response of exchange rates to statement shocks in Figure 14.

$$
E\left(\Delta s_{t}\right)=\sum_{\tau=\tau_{1}}^{\tau_{m}} E\left(\frac{\partial \Delta s_{t}}{\partial y_{t}(\tau)}\right) \varepsilon_{t}^{T S}(\tau)+E\left(\frac{\partial \Delta s_{t}}{\partial v_{t}}\right) \varepsilon_{t}^{s t}+E\left(\frac{\partial \Delta s_{t}}{\partial \omega_{t}}\right) \varepsilon_{t}^{p c}
$$


$\varepsilon_{t}^{p c}$ is shock to the introductory statement of the press conference on day $t$. Press conference shock on a given announcement day is the difference between the sentiment score of the current and most recent introductory statement of the Fed chair press conference. Figure 14 provides further evidence that press conferences do not drive the effect of statement shocks on exchange rates.

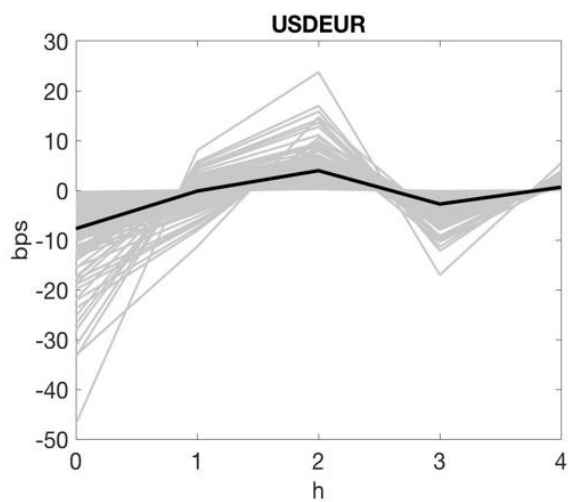

(a) $\varepsilon_{t}^{s t}>0$

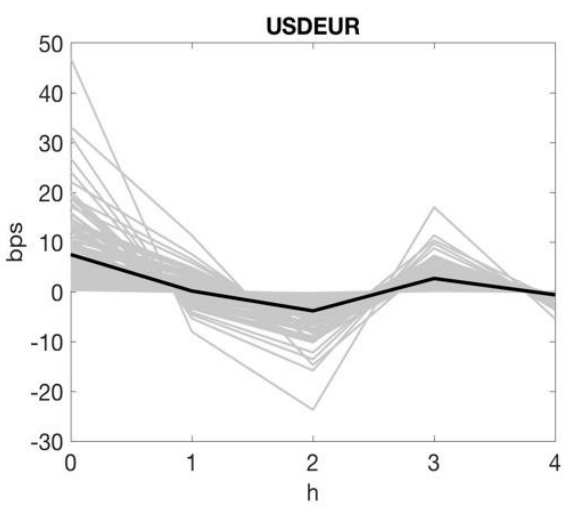

(d) $\varepsilon_{t}^{s t}<0$

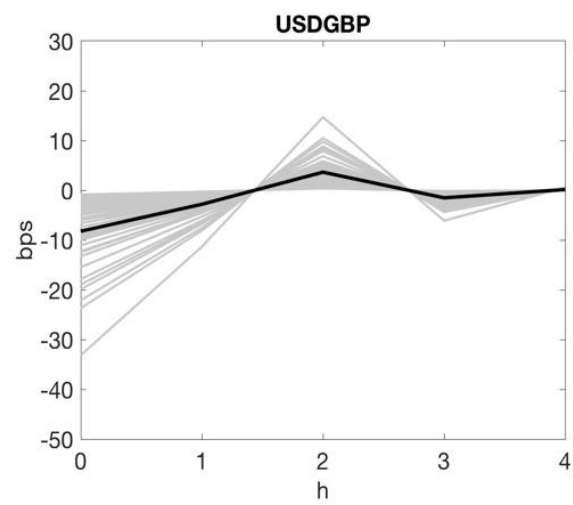

(b) $\varepsilon_{t}^{s t}>0$

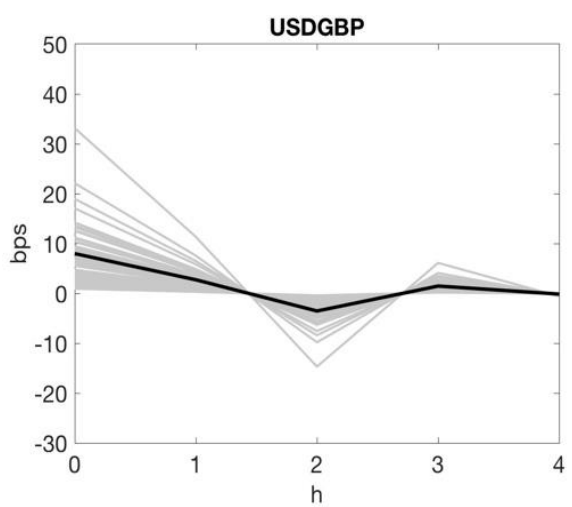

(e) $\varepsilon_{t}^{s t}<0$

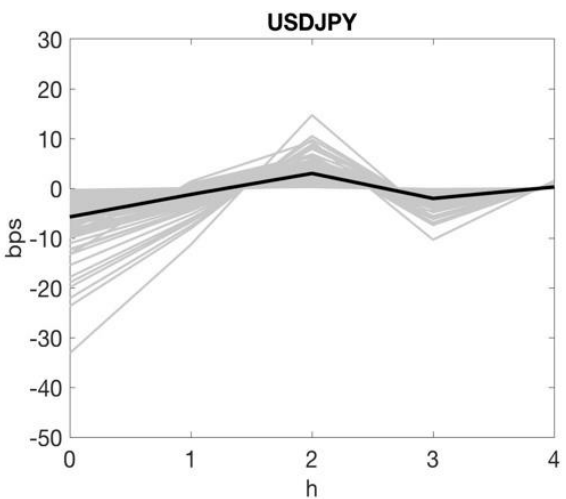

(c) $\varepsilon_{t}^{s t}>0$

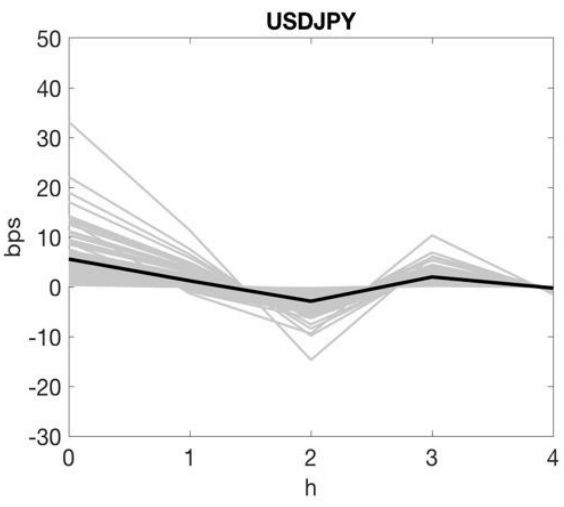

(f) $\varepsilon_{t}^{s t}<0$

Figure 14. Response of U.S. Dollar exchange rates to statement shocks after controlling for the effect of Fed chair press conferences

\section{Discussion}

This section addresses two questions related to the results of section 3. First, is the response of exchange rates to statement shocks economically significant? Second, what explains the effect of statement shocks on exchange rates?

Section 3 shows that the average response of various dollar and euro exchange rates to statement shocks is between 5 and 12 basis points. In this section, I decompose the response of exchange rates to monetary policy shocks and measure the contribution of term structure shocks to exchange rate changes. Comparing the contribution of term structure shocks and statement shocks sheds light on the relative importance of statement shocks in accounting for changes in exchange rates on announcement days. The response of exchange rate to term structure shocks, denoted by $R_{t}^{T S}$, is computed using the following equation

$$
R_{t}^{T S}=\sum_{\tau=\tau_{1}}^{\tau_{m}} E\left(\frac{\partial \Delta s_{t}}{\partial y_{t}(\tau)}\right) \varepsilon_{t}^{T S}(\tau) .
$$

I compute and report $R_{t}^{T S}$ in four separate figures for contractionary and expansionary term structure shocks and positive and negative statement shocks. Figure 15 shows the response of exchange rates to term structure shocks when FOMC announces a contractionary policy $\left(\varepsilon_{t}^{T S}(5)>0\right)$, and the sentiment of the monetary policy statement is more positive than before $\left(\varepsilon_{t}^{s t}>0\right)$. The charts indicate that higher interest rates lead to an appreciation of the dollar. 
While positive statement shocks lead to an appreciation of the dollar, the combination of contractionary interest rate policy and positive statement leads to modest appreciation of the dollar as the effect of term structure shocks dominates the effect of statement shocks for all exchange rates except USD/GBP. Figures 16, 17, and 18 show the impulse response of exchange rates to term structure shocks for combinations of contractionary policy and negative statement, expansionary policy and positive statement, and expansionary policy and negative statement.

The general pattern in the results is that the dollar appreciates following the announcement of a contractionary policy and depreciates when the FOMC announces an expansionary policy. The effect of term structure shocks on euro exchange rates is computed and reported in Figures 19-22. The size of exchange rate response to statement shocks relative to that of term structure shocks varies across different exchange rates and the combination of interest rate and communication policy but Figures 15-22 show that the response of exchange rates to statement shocks and term structure shocks are comparable in terms of magnitude.
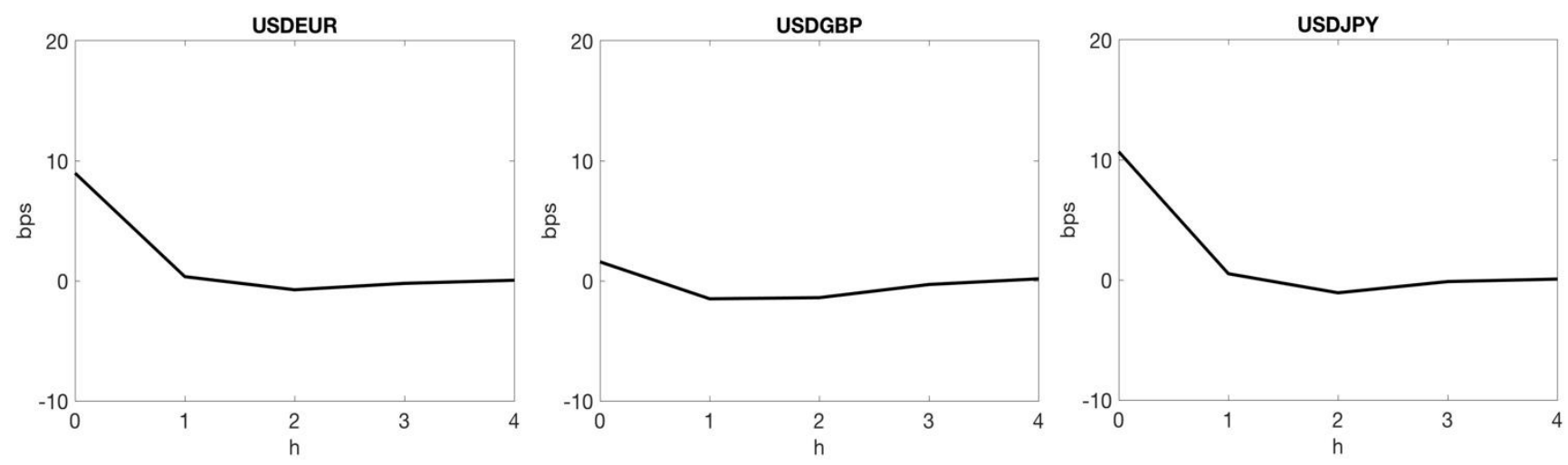
(a) $\varepsilon_{t}^{T S}>0$
(b) $\varepsilon_{t}^{T S}>0$
(c) $\varepsilon_{t}^{T S}>0$

Figure 15. Response of U.S. Dollar exchange rates to term structure shocks: Positive statement shocks $\left(\varepsilon_{t}^{s t}>0\right)$ and

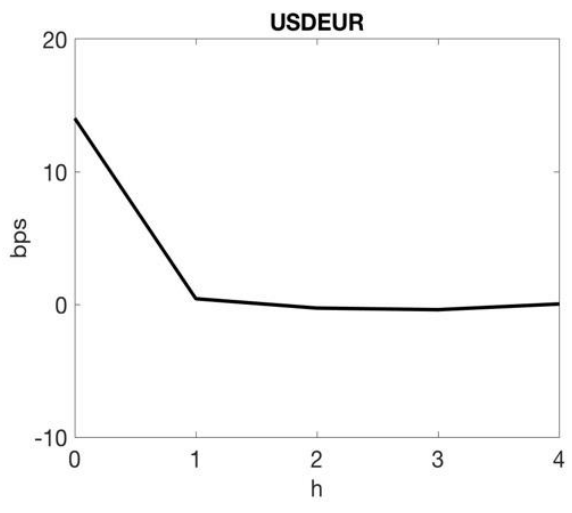

(a) $\varepsilon_{t}^{T S}>0$

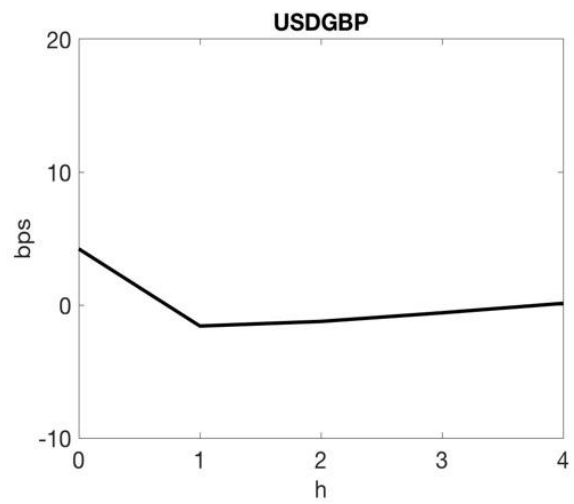

contractionary policy $\left(\varepsilon_{t}^{T S}>0\right)$

(b) $\varepsilon_{t}^{T S}>0$

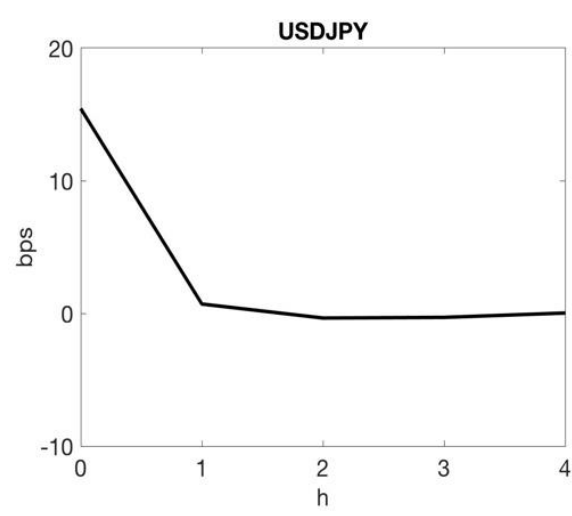

(c) $\varepsilon_{t}^{T S}>0$

Figure 16. Response of U.S. Dollar exchange rates to term structure shocks: Negative statement shocks $\left(\varepsilon_{t}^{s t}<0\right)$ and contractionary policy $\left(\varepsilon_{t}^{T S}>0\right)$ 

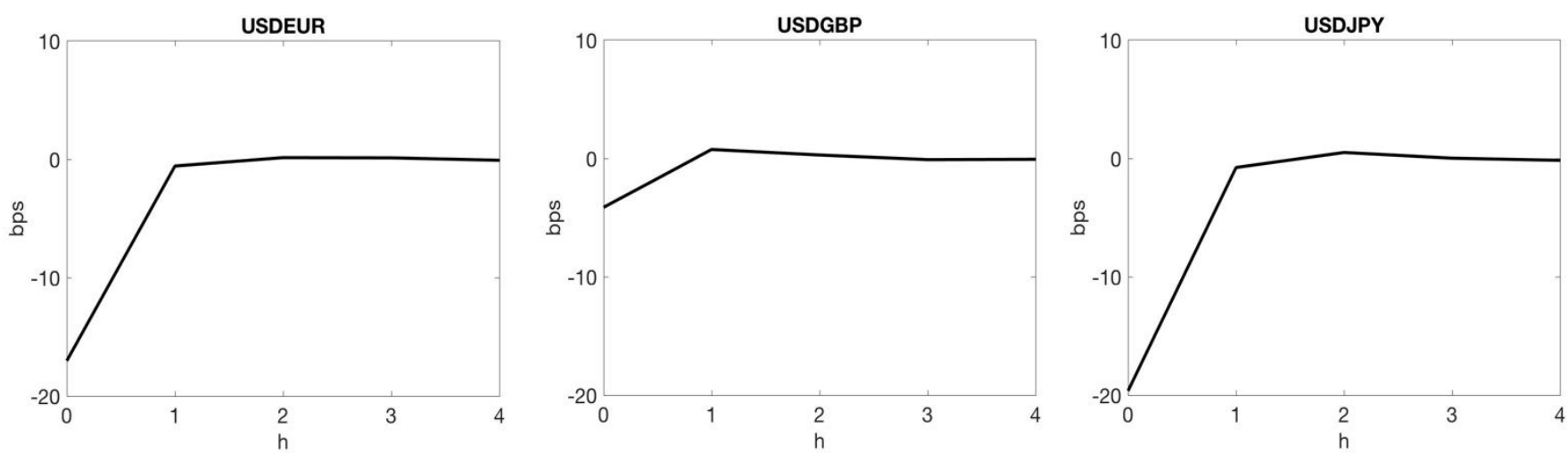

(a) $\varepsilon_{t}^{T S}<0$

(b) $\varepsilon_{t}^{T S}<0$

(c) $\varepsilon_{t}^{T S}<0$

Figure 17. Response of U.S. Dollar exchange rates to term structure shocks: Positive statement shocks $\left(\varepsilon_{t}^{s t}>0\right)$ and expansionary policy $\left(\varepsilon_{t}^{T S}<0\right)$

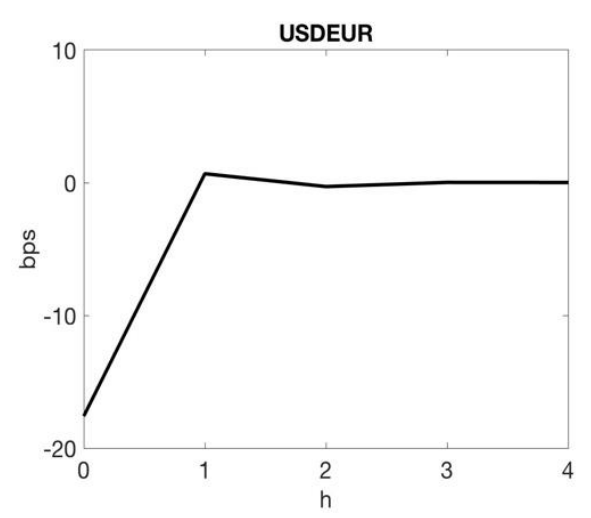

(a) $\varepsilon_{t}^{T S}<0$

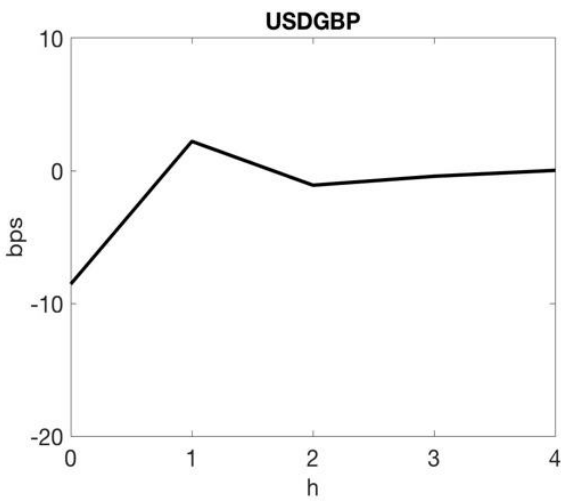

(b) $\varepsilon_{t}^{T S}<0$

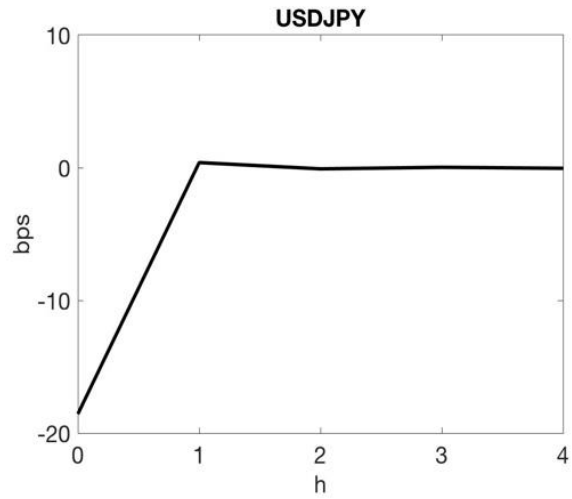

(c) $\varepsilon_{t}^{T S}<0$

Figure 18. Response of U.S. Dollar exchange rates to term structure shocks: Negative statement shocks $\left(\varepsilon_{t}^{s t}<0\right)$ and expansionary policy $\left(\varepsilon_{t}^{T S}<0\right)$

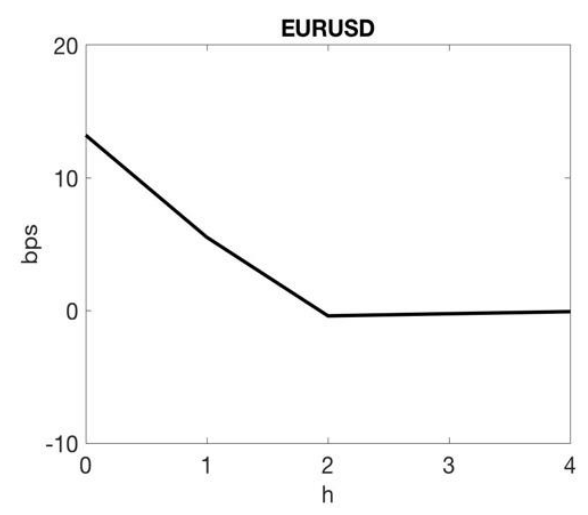

(a) $\varepsilon_{t}^{T S}>0$

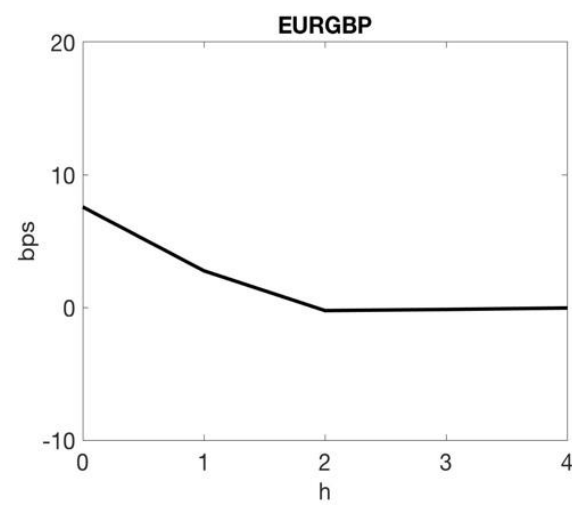

(b) $\varepsilon_{t}^{T S}>0$

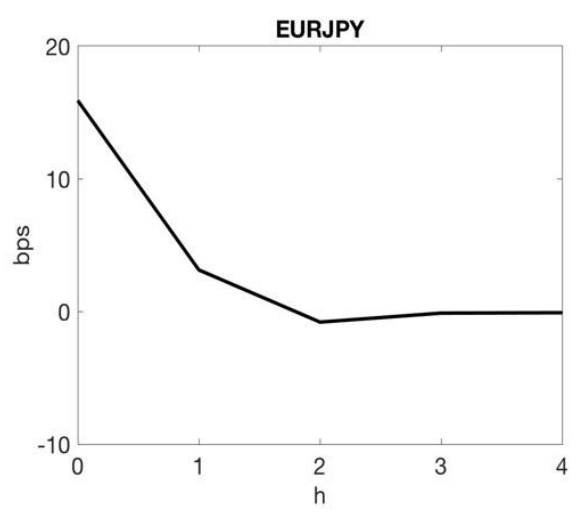

(c) $\varepsilon_{t}^{T S}>0$

Figure 19. Response of Euro exchange rates to term structure shocks: Positive sentiment shocks $\left(\varepsilon_{t}^{s t}>0\right)$ and contractionary policy $\left(\varepsilon_{t}^{T S}>0\right)$ 


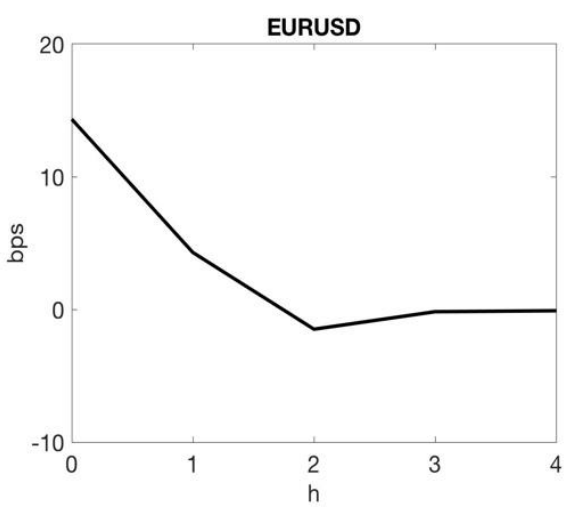

(a) $\varepsilon_{t}^{T S}>0$

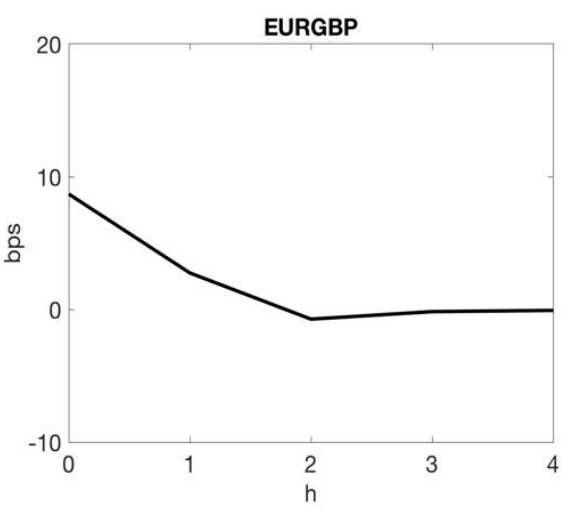

(b) $\varepsilon_{t}^{T S}>0$

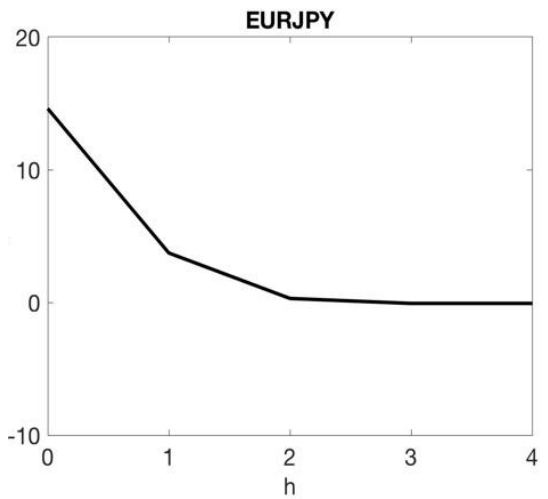

(c) $\varepsilon_{t}^{T S}>0$

Figure 20. Response of Euro exchange rates to term structure shocks: Negative statement shocks $\left(\varepsilon_{t}^{s t}<0\right)$ and contractionary policy $\left(\varepsilon_{t}^{T S}>0\right)$

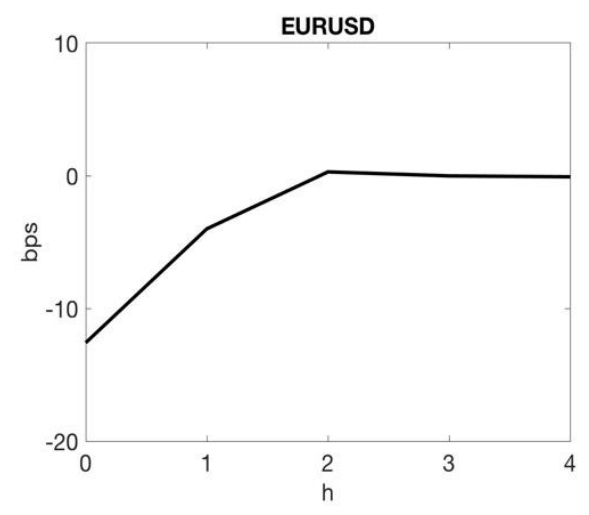

(a) $\varepsilon_{t}^{T S}<0$

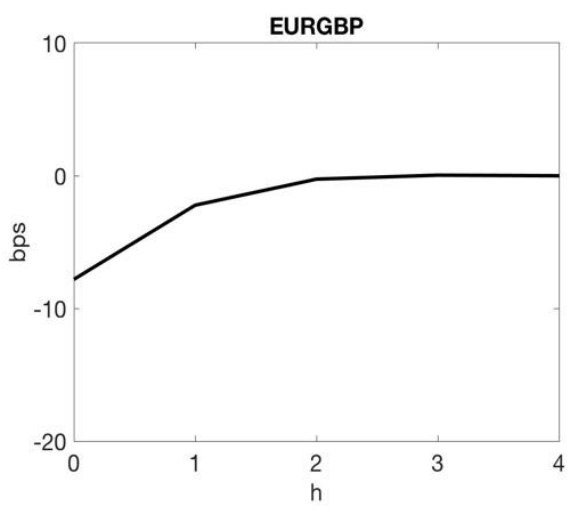

(b) $\varepsilon_{t}^{T S}<0$

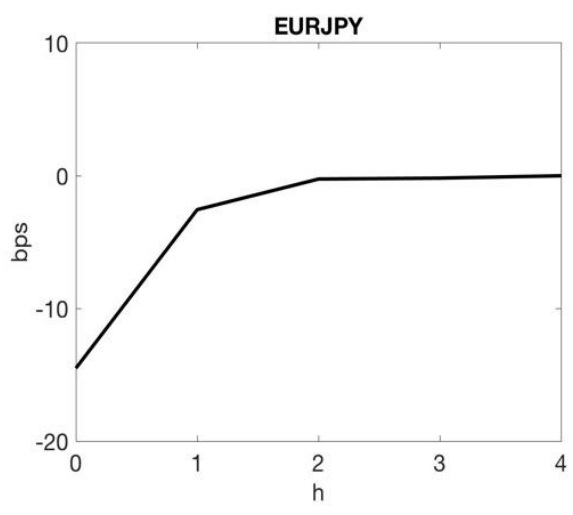

(c) $\varepsilon_{t}^{T S}<0$

Figure 21. Response of Euro exchange rates to term structure shocks: Positive statement shocks $\left(\varepsilon_{t}^{s t}>0\right)$ and expansionary policy $\left(\varepsilon_{t}^{T S}<0\right)$

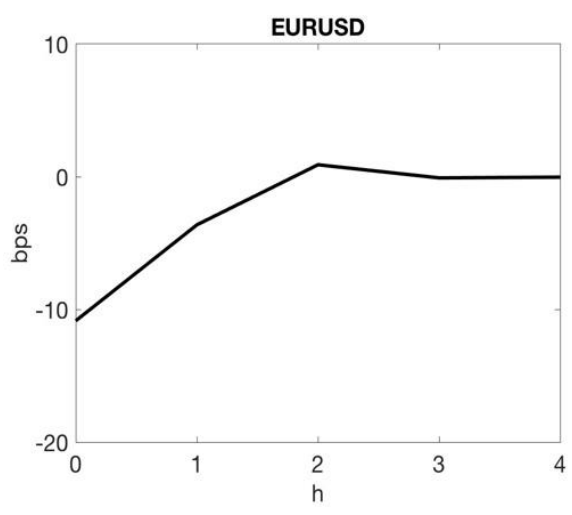

(a) $\varepsilon_{t}^{T S}<0$

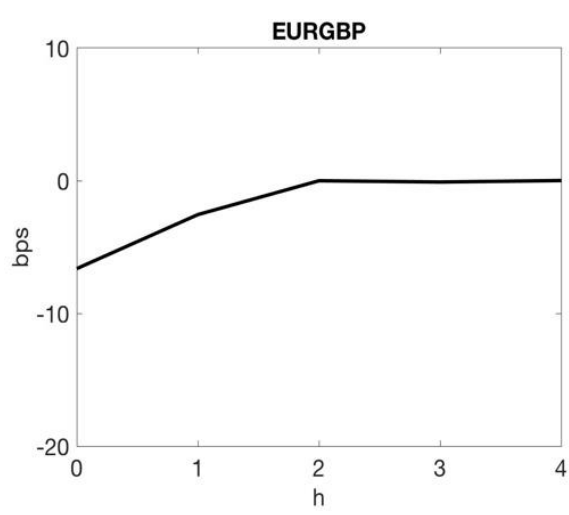

(b) $\varepsilon_{t}^{T S}<0$

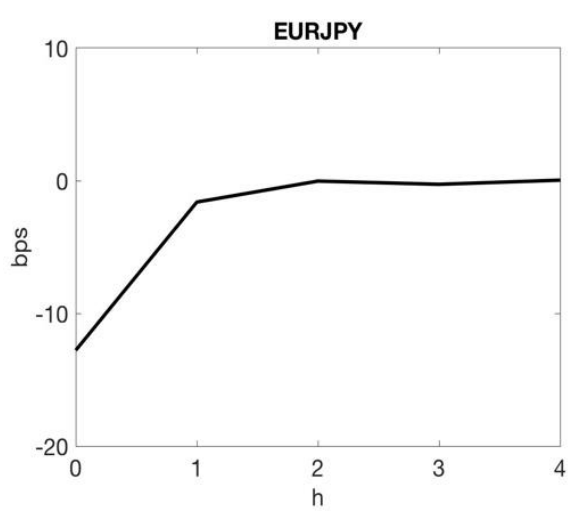

(c) $\varepsilon_{t}^{T S}<0$

Figure 22. Response of Euro exchange rates to term structure shocks: Negative statement shocks $\left(\varepsilon_{t}^{s t}<0\right)$ and expansionary policy $\left(\varepsilon_{t}^{T S}<0\right)$

The second question about the earlier results is that what explains the effect of statement shocks on exchange rates. 
While I acknowledge that it is not easy to be sure about what explains the effect of statements, I discuss some possible explanations. One possibility is that private sector agents believe that the central bank is better informed about the economy's current stance, and they update their expectations following the release of monetary policy statements. The central bank can communicate its expectations by providing forecasts of future macroeconomic indicators or using positive or negative words to describe its assessment of the economy. In section 3.3, I show that controlling for the Fed's forecast of macro indicators does not eliminate the effect of statement shocks. Statements have informational value beyond what could be explained by term structure shocks or the Fed's forecast of near-term macro variables. Nakamura and Steinsson (2018) show that private sector agents update their real output expectations after U.S. monetary policy announcements. Maćkowiak (2007) shows that U.S. monetary policy affects the price level and real output of a typical emerging market more than those of the United States. It is plausible to think that the sentiment of statements influences private sector expectations of domestic and international macro fundamentals. International spillover of U.S. monetary policy is significant, so statement shocks affect expectations of international macro fundamentals more than those of domestic fundamentals. Since the exchange rate is the present value of future relative macro fundamentals, dollar exchange rates respond negatively to FOMC statement shocks. Private sector agents sell the dollar to buy other currencies when the sentiment of the FOMC statement improves. The spillover of ECB policies to countries outside the monetary union is limited, so agents buy the euro and sell other currencies when the sentiment of the ECB statement improves.

Statement shocks could also affect exchange rates by changing the private sector's attitude toward risk. If private sector agents believe that the central bank possesses superior tools to assess the macroeconomic risks, their attitude toward risk changes after a positive or negative change in the sentiment of monetary policy statements. As risk aversion rises (falls), there is more (less) demand for safe-haven currency, and the dollar appreciates (depreciates). Euro is not considered a safe-haven currency, so it appreciates (depreciates) when ECB releases a more positive (negative) statement after a monetary policy meeting. The statements could affect exchange rates by changing expectations of macro fundamentals or risk aversion of the private sector. Both effects could be classified as the information effect because they rely on the assumption that central bankers possess superior information about the economy.

Another possible explanation is that interpreting monetary policy statements is an inherently difficult task, and investors might need some time to extract all the statements' information content. As a result of this uncertainty, the dollar depreciates vis-à-vis other currencies on FOMC announcement days. Mueller et al. (2017) document the negative excess return of the U.S. dollar on FOMC announcement days and attribute the excess return of a short dollar position to monetary policy uncertainty. If the general ambiguity of statements or monetary policy uncertainty is the main reason for the effect of statement shocks on exchange rates, the currency should depreciate on central bank announcement days regardless of the sign of statement shock. The results of section 3 consistently show the dependence of exchange rate response to the direction of statement shocks. I conclude that the results could not be explained by the ambiguity of statements or monetary policy uncertainty.

\subsection{Conclusion}

I use Google Cloud's Natural Language API to measure and track changes in the sentiment of post-meeting statements released on FOMC and ECB announcement days. The main advantage of Google's Natural Language tool is its objectivity in detecting the prevailing sentiment of words used in the statements. I break monetary policy shocks into term structure shocks and statement shocks. Term structure shocks are defined as changes in interest rates across different maturities, and statement shocks are defined as changes in the sentiment score of consecutive statements. I estimate a VAR model of interest rates, exchange rate, and statement shocks and find the impulse response of various dollar and euro exchange rates to FOMC and ECB statement shocks. The results reveal a negative relationship between the value of the U.S. dollar and FOMC statement shocks and a positive relationship between the euro and ECB statement shocks.

When an FOMC statement is more optimistic than the previous one, private sector agents raise their expectations of U.S. macro fundamentals. Knowing about the significant international spillover of U.S. monetary policy, agents raise their expectations of international macro fundamentals more than their expectations of U.S. fundamentals. The dollar depreciates as a result of lower expectations of relative macro fundamentals. ECB monetary policies affect the economic fundamentals of the countries in the monetary union more than those of countries outside the union. Hence, an improvement in the sentiment of the ECB statement raises expectations of relative macro fundamentals, and the euro appreciates relative to other currencies. Future research could expand this study by investigating the link between monetary policy statements and exchange rates for other major economies. There is also the potential for 
research projects that employ other machine learning tools to examine the link between the statements and asset prices.

\section{References}

Cochrane, J. H., \& Piazzesi, M. (2009). Decomposing the yield curve. In AFA 2010 Atlanta Meetings Paper. https://doi.org/10.2139/ssrn.1333274

Conrad, C., \& Lamla, M. J. (2010). The high-frequency response of the EUR-USD exchange rate to ECB communication. Journal of Money, Credit and Banking, 42(7), 1391-1417. https://doi.org/10.1111/j.1538-4616.2010.00346.x

Evans, M. D., \& Lyons, R. K. (2002). Order flow and exchange rate dynamics. Journal of political economy, 110(1), 170-180. https://doi.org/10.1086/324391

Fratzscher, M., Duca, M. L., \& Straub, R. (2016). ECB unconventional monetary policy: Market impact and international spillovers. IMF Economic Review, 64(1), 36-74. https://doi.org/10.1057/imfer.2016.5

Guo, Y. (2017). Order flow and exchange rate dynamics in continuous time: New evidence from martingale regression. International Journal of Economics and Financial Issues, 7(2), 507. https://doi.org/10.2139/ssrn.3013781

Gürkaynak, R. S., Sack, B., \& Swanson, E. (2005). The sensitivity of long-term interest rates to economic news: Evidence and implications for macroeconomic models. American economic review, 95(1), 425-436. https://doi.org/10.1257/0002828053828446

Gürkaynak, R. S., Sack, B., \& Wright, J. H. (2007). The US Treasury yield curve: 1961 to the present. Journal of monetary Economics, 54(8), 2291-2304. https://doi.org/10.1016/j.jmoneco.2007.06.029

Hausman, J., \& Wongswan, J. (2011). Global asset prices and FOMC announcements. Journal of International Money and Finance, 30(3), 547-571. https://doi.org/10.1016/j.jimonfin.2011.01.008

Inoue, A., \& Rossi, B. (2019). The effects of conventional and unconventional monetary policy on exchange rates. Journal of International Economics, 118, 419-447. https://doi.org/10.1016/j.jinteco.2019.01.015

Jansen, D. J., \& De Haan, J. (2005). Talking heads: the effects of ECB statements on the euro-dollar exchange rate. Journal of International Money and Finance, 24(2), 343-361. https://doi.org/10.1016/j.jimonfin.2004.12.009

Kim, S. (2001). International transmission of US monetary policy shocks: Evidence from VAR's. Journal of Monetary Economics, 48(2), 339-372. https://doi.org/10.1016/S0304-3932(01)00080-0

Kuttner, K. N. (2001). Monetary policy surprises and interest rates: Evidence from the Fed funds futures market. Journal of monetary economics, 47(3), 523-544. https://doi.org/10.1016/S0304-3932(01)00055-1

Lucca, D. O., \& Trebbi, F. (2009). Measuring central bank communication: an automated approach with application to FOMC statements (No. w15367). National Bureau of Economic Research. https://doi.org/10.3386/w15367

Maćkowiak, B. (2007). External shocks, US monetary policy and macroeconomic fluctuations in emerging markets. Journal of monetary economics, 54(8), 2512-2520. https://doi.org/10.1016/j.jmoneco.2007.06.021

Mueller, P., Tahbaz-Salehi, A., \& Vedolin, A. (2017). Exchange rates and monetary policy uncertainty. The Journal of Finance, 72(3), 1213-1252. https://doi.org/10.1111/jofi.12499

Nakamura, E., \& Steinsson, J. (2018). High-frequency identification of monetary non-neutrality: the information effect. The Quarterly Journal of Economics, 133(3), 1283-1330. https://doi.org/10.1093/qje/qjy004

De Pooter, M. (2007). Examining the Nelson-Siegel class of term structure models: In-sample fit versus out-of-sample forecasting performance. Available at SSRN 992748. https://doi.org/10.2139/ssrn.992748

Romer, C. D., \& Romer, D. H. (2000). Federal Reserve information and the behavior of interest rates. American Economic Review, 90(3), 429-457. https://doi.org/10.1257/aer.90.3.429

\section{Copyrights}

Copyright for this article is retained by the author(s), with first publication rights granted to the journal.

This is an open-access article distributed under the terms and conditions of the Creative Commons Attribution license (http://creativecommons.org/licenses/by/4.0/). 